\title{
Construction Guidelines for High R-Value Walls without Exterior Rigid Insulation
}

Lois B. Arena

Consortium for Advanced Residential Buildings

July 2016
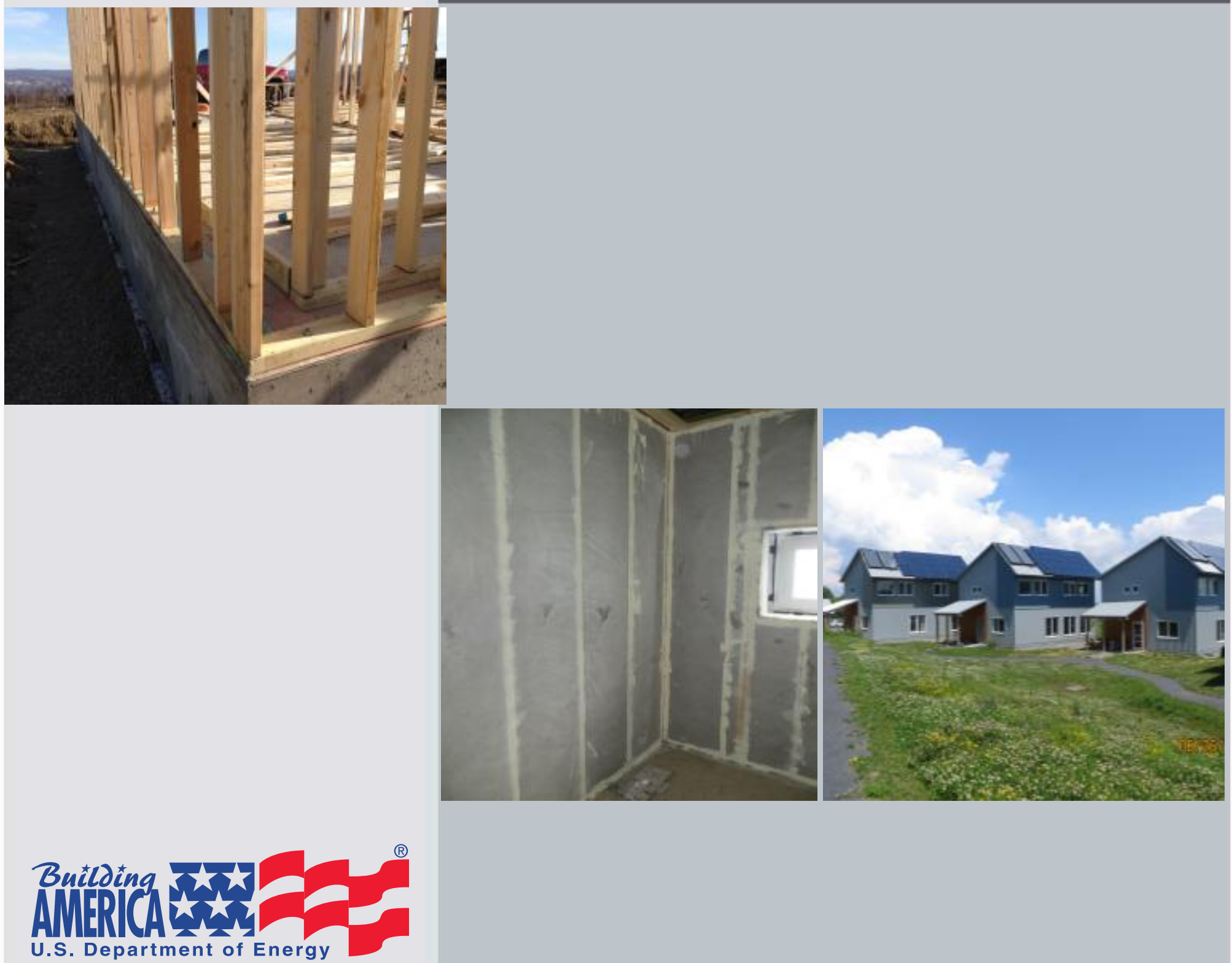


\section{NOTICE}

This report was prepared as an account of work sponsored by an agency of the United States government. Neither the United States government nor any agency thereof, nor any of their employees, subcontractors, or affiliated partners makes any warranty, express or implied, or assumes any legal liability or responsibility for the accuracy, completeness, or usefulness of any information, apparatus, product, or process disclosed, or represents that its use would not infringe privately owned rights. Reference herein to any specific commercial product, process, or service by trade name, trademark, manufacturer, or otherwise does not necessarily constitute or imply its endorsement, recommendation, or favoring by the United States government or any agency thereof. The views and opinions of authors expressed herein do not necessarily state or reflect those of the United States government or any agency thereof.

Available electronically at SciTech Connect http:/www.osti.gov/scitech

Available for a processing fee to U.S. Department of Energy

and its contractors, in paper, from:

U.S. Department of Energy

Office of Scientific and Technical Information

P.O. Box 62

Oak Ridge, TN 37831-0062

OSTI http://www.osti.gov

Phone: 865.576.8401

Fax: 865.576.5728

Email: reports@osti.gov

Available for sale to the public, in paper, from:

U.S. Department of Commerce

National Technical Information Service

5301 Shawnee Road

Alexandria, VA 22312

NTIS http://www.ntis.gov

Phone: 800.553 .6847 or 703.605 .6000

Fax: 703.605.6900

Email: orders@ntis.gov 


\title{
Construction Guidelines for High R-Value Walls without Exterior Rigid Insulation
}

\author{
Prepared for: \\ The National Renewable Energy Laboratory \\ On behalf of the U.S. Department of Energy's Building America Program \\ Office of Energy Efficiency and Renewable Energy \\ 15013 Denver West Parkway \\ Golden, CO 80401 \\ NREL Contract No. DE-AC36-08GO28308 \\ Prepared by: \\ Lois B. Arena, PE \\ Steven Winter Associates, Inc. \\ Consortium for Advanced Residential Buildings \\ 61 Washington Street \\ Norwalk, CT 06854 \\ NREL Technical Monitor: Stacey Rothgeb \\ Prepared under Subcontract No. KNDJ-0-40342-05
}

July 2016 
The work presented in this report does not represent performance of any product relative to regulated minimum efficiency requirements.

The laboratory and/or field sites used for this work are not certified rating test facilities. The conditions and methods under which products were characterized for this work differ from standard rating conditions, as described.

Because the methods and conditions differ, the reported results are not comparable to rated product performance and should only be used to estimate performance under the measured conditions. 


\section{Contents}

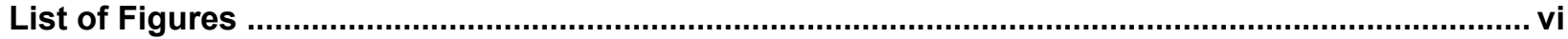

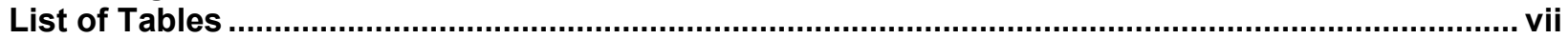

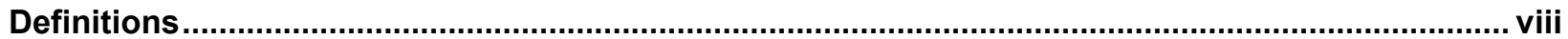

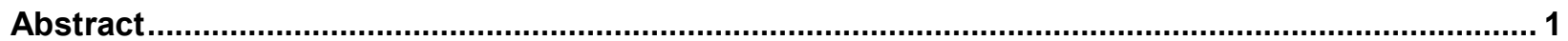

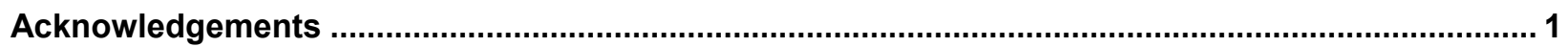

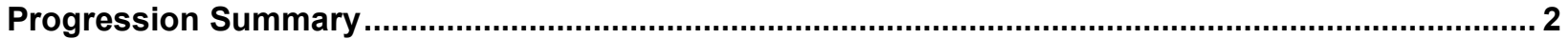

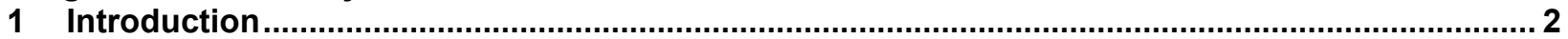

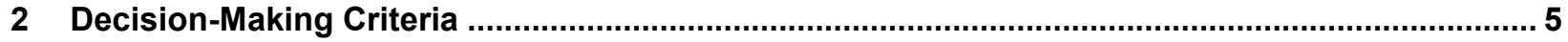

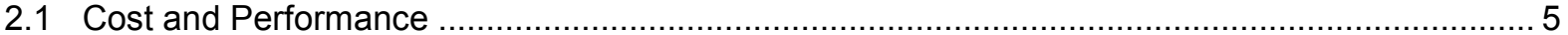

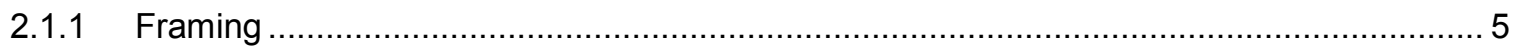

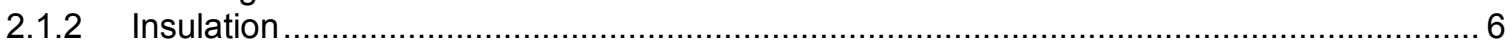

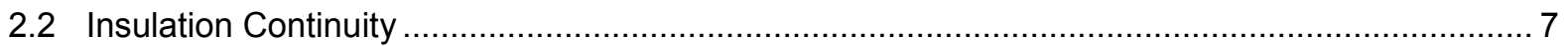

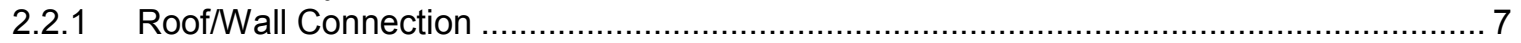

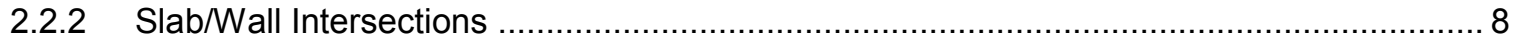

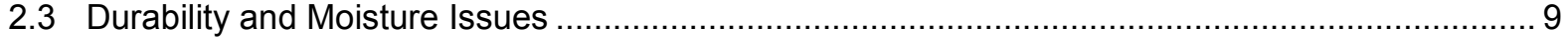

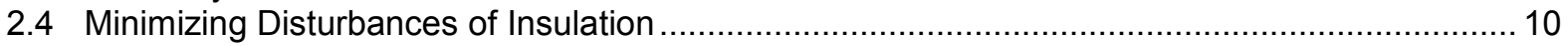

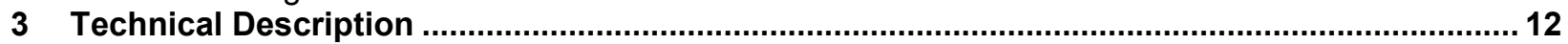

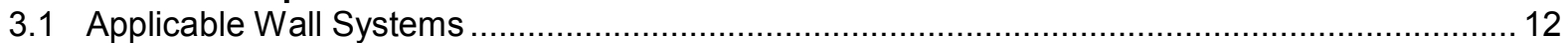

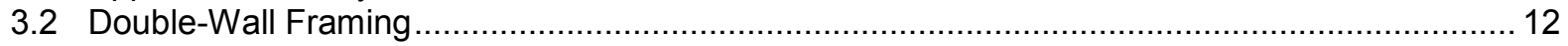

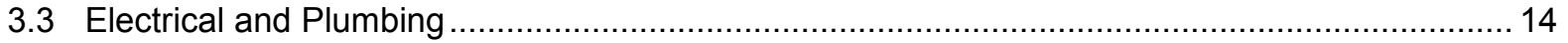

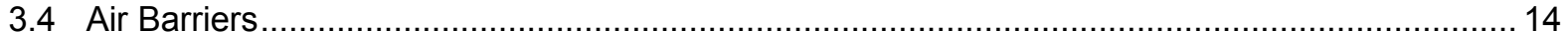

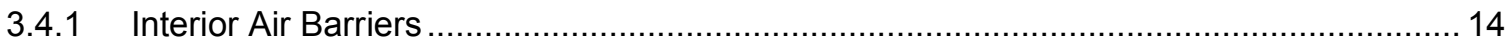

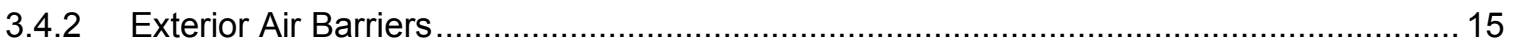

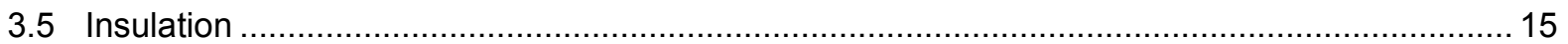

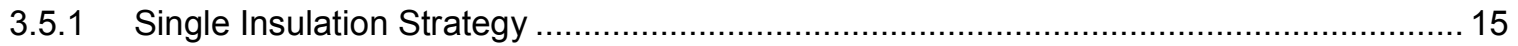

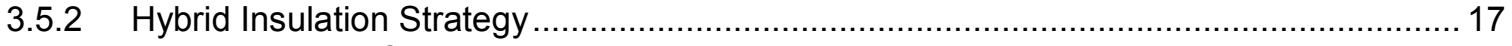

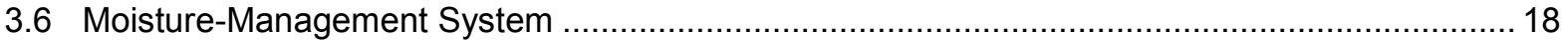

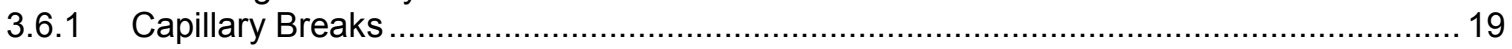

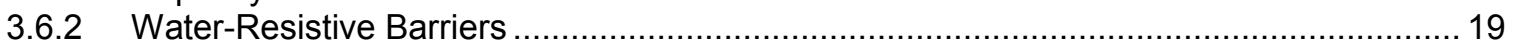

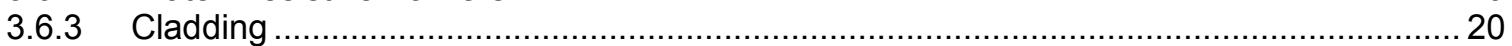

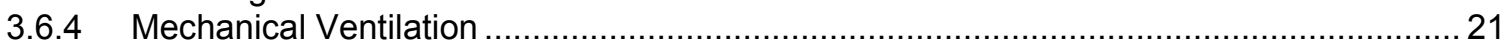

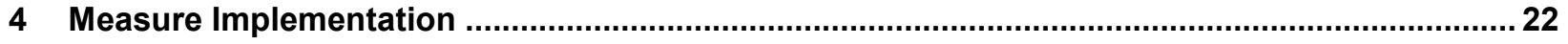

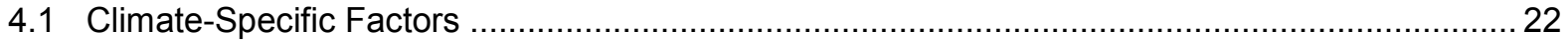

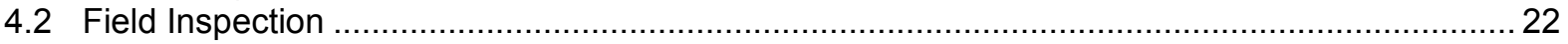

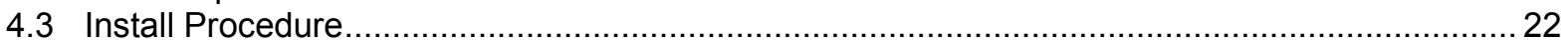

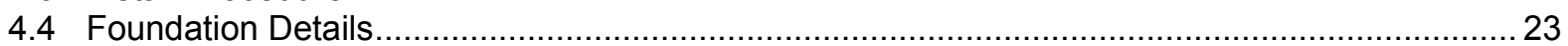

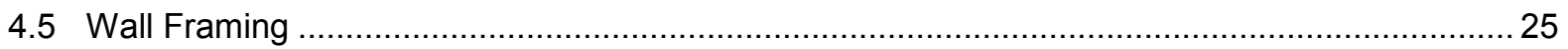

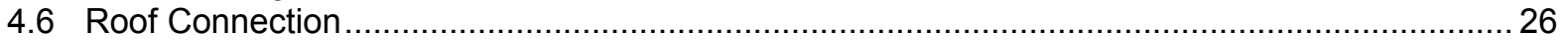

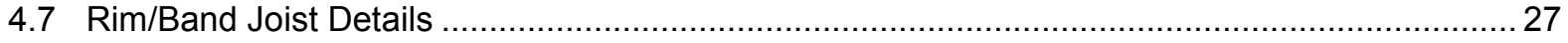

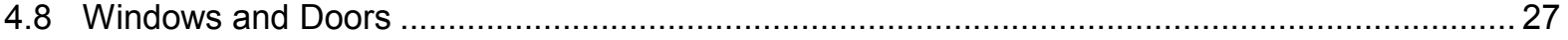

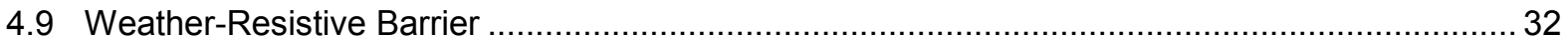

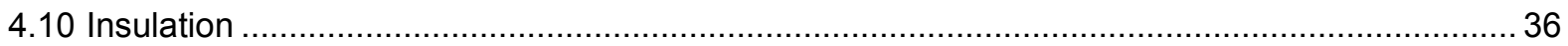

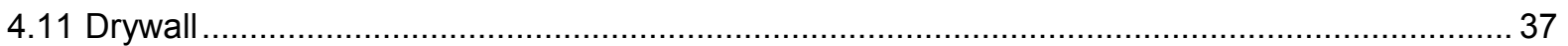

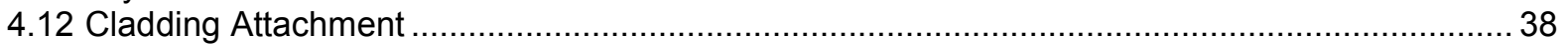

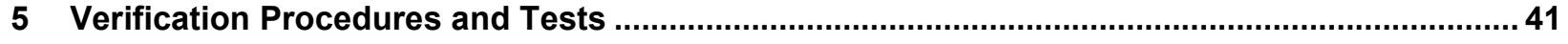

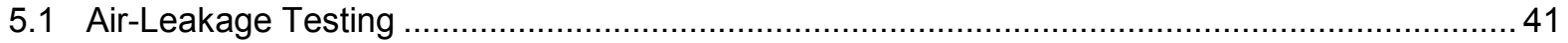

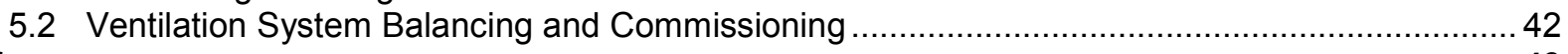

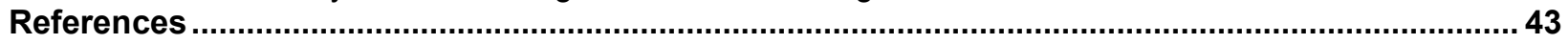

Appendix A: Compliance with U.S. Department of Energy Zero Energy Ready Home Criteria........ 44 


\section{List of Figures}

Figure 1. Double-wall construction

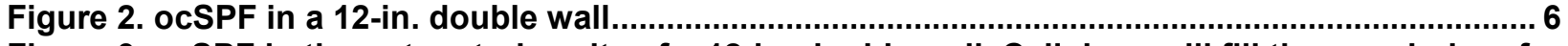

Figure 3. ccSPF in the outer stud cavity of a 12-in. double wall. Cellulose will fill the remainder of the cavity.

Figure 4. Full-depth cellulose insulation in a 12-in. double wall.................................................... 6

Figure 5. Roof/wall intersection showing good continuity of insulation ........................................... 7

Figure 6. A shallow roof pitch resulting in the inability to install full-depth ceiling insulation over the entire depth of the wall cavity

Figure 7. ccSPF installed over the outer edge of the double wall to the desired R-value for the ceiling

Figure 8. Flashing over slab edge insulation was taped to the sheathing using the manufacturer's approved tape. The vented cladding was then attached with $3 / 4$-in. furring strips, and it overlapped the flashing.

Figure 9. Insulation netting surrounds vents and plumbing penetrations in an exterior double wall.

Figure 10. Two-stud corners can be used for both the interior and exterior walls in the double-wall assembly.

Figure 11. Reduced framing around windows on the interior wall .............................................. 12

Figure 12. Reductions in framing around the openings allows for more insulation in headers. ..... 13

Figure 13. Windows in double walls: (left) a framed window opening and (right) a set window ..... 14

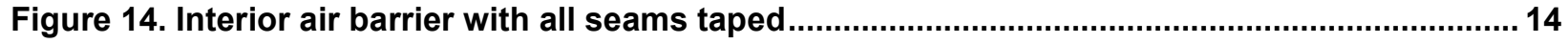

Figure 15. Exterior air barrier with all seams taped .................................................................. 14

Figure 16. Double wall before and after insulation with dense-blown cellulose ............................... 16

Figure 17. Incomplete capillary break. It should be installed the entire depth of the wall to keep

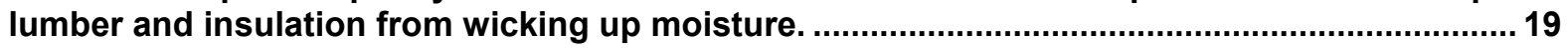

Figure 18. Example of a building wrap being used for the WRB ................................................ 20

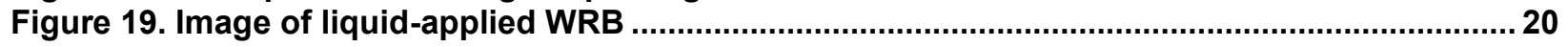

Figure 20. Vertical furring strips create a vent space for horizontal fiber cement siding............... 21

Figure 21. Horizontal furring was used to attach a corrugated metal panel siding that allows vertical draining and venting of the sheathing.

Figure 22. Typical blower door equipment used to detect air leakage through the building envelope 


\section{List of Tables}

Table 1. Additional Lumber Costs for Double Walls per 100 Linear Feet .. 5

Table 2. 2012 IRC Requirements for Walls with a Class III Vapor Retarder

Table 3. Thermal Effects of Framing Factors on Double Walls......................................................13

Table 4. R-Values for Double Walls of Varying Thicknesses ...................................................... 17 


\section{Definitions}

$\begin{array}{ll}\text { ccSPF } & \text { Closed-cell spray polyurethane foam } \\ \text { IRC } & \text { International Residential Code } \\ \text { ocSPF } & \text { Open-cell spray polyurethane foam }\end{array}$

WRF Water-resistive barrier 


\section{Abstract}

High R-value wall assemblies (R-40 and above) are gaining popularity in the market due to programs such as the U.S. Department of Energy Zero Energy Ready Home program, Passive House, Net Zero Energy Home challenges in several states, and highly incentivized retrofit programs. In response to this demand, several builders have successfully used double-wall systems to achieve higher R-values in thicker, framed walls. To builders of conventional stickframed homes, often one of the most appealing features of double-wall systems is that there are very few new exterior details. Exterior sheathings, structural bracings, house wraps or building paper, window and door flashings, and siding attachments are usually identical to good details in conventional framed-wall systems.

However, although the details in double-wall systems are very similar to those in conventional stick framing, there is sometimes less room for error. Several studies have confirmed colder temperatures of exterior sheathing in high R-value wall assemblies that do not have exterior rigid foam insulation. These colder temperatures can lead to increased chances for condensation from air exfiltration, and they have the potential to result in moisture-related problems (Straube and Smegal 2009, Arena 2014, Ueno 2015).

The information presented in this guide is intended to reduce the risk of failure in these types of assemblies, increase durability, and reduce material brought to landfills due to failures and resulting decay. Although this document focuses on double-wall framing techniques, the majority of the information about how to properly construct and finish high R-value assemblies is applicable to all wall assemblies that do not have foam insulation installed on the exterior of the structural sheathing. The techniques presented have been shown through field studies to reduce the likelihood of mold growth and moisture-related damage and are intended for builders, framing contractors, architects, and consultants involved in designing and building superinsulated homes. The information is applicable to both new construction and gut-rehabilitation projects in Climate Zones 5 and higher.

\section{Author}

This is the first edition of this guide. It was authored by Lois B. Arena, PE, of Steven Winter Associates, Inc., lead for the U.S. Department of Energy Building America team Consortium for Advanced Residential Buildings.

\section{Acknowledgements}

Steven Winter Associates acknowledges the U.S. Department of Energy Building America program and their funding and support for the development of this technical report as well as the research that informed it. Steven Winter Associates would like to thank William Anderson from Metric Corporation and Michael Carpenter and the project manager Kendall Carpenter from AquaZephyr, LLC, for their continued cooperation and dedication throughout the studies that informed this guideline. Special thanks also to the residents of the Third Residential Ecovillage Experience (TREE) neighborhood at EcoVillage in Ithaca, New York, for their continued support, cooperation, and the use of their homes. 


\section{Progression Summary}

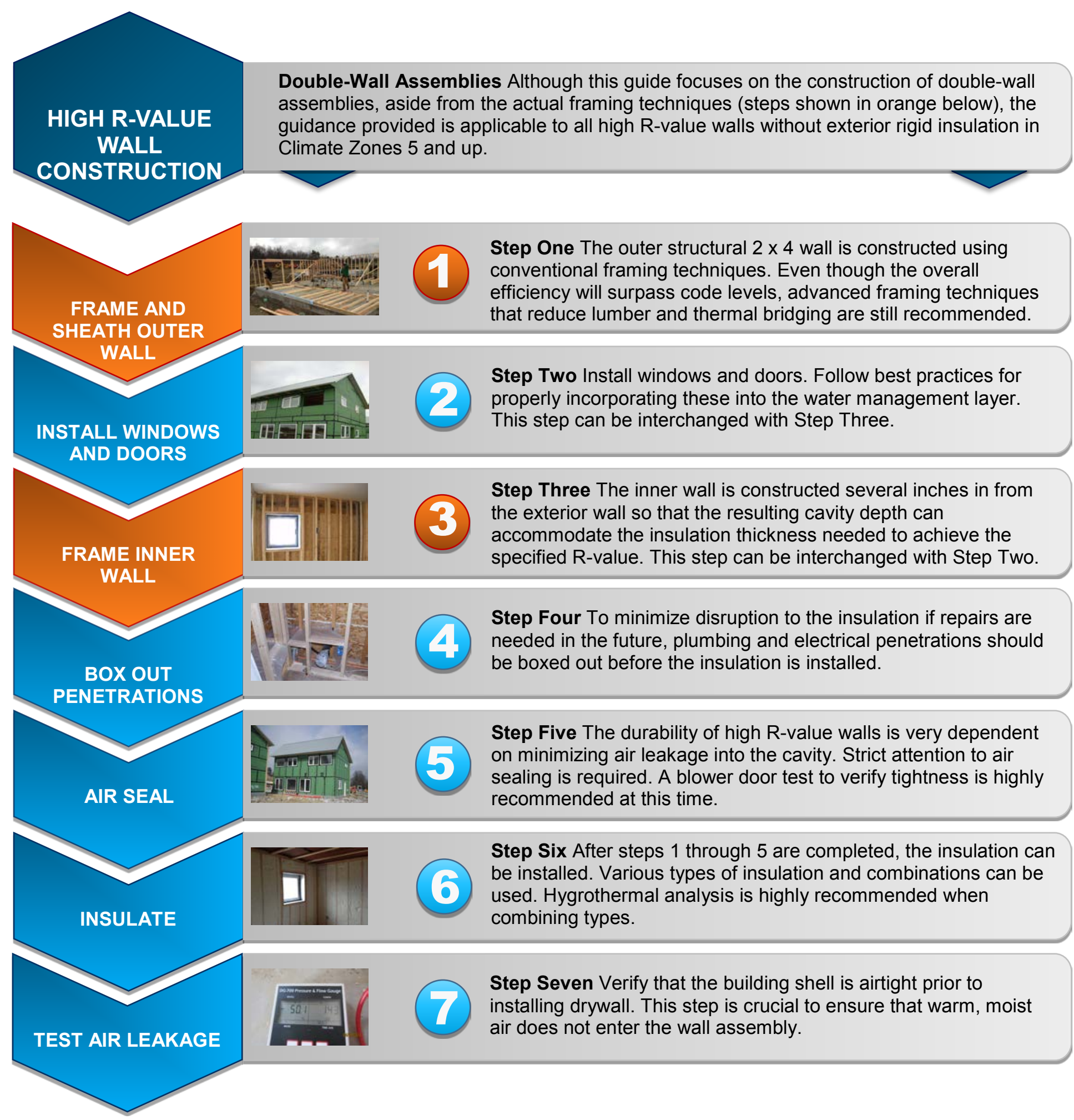




\section{Introduction}

During the last several years, the focus on energy efficiency has increased, and so have the requirements of energy-efficiency codes and performance programs. In fact, upon adoption of the 2012 International Energy Conservation Code, homes built in Climate Zone 6 and higher are required to either install insulating sheathing on the exterior of the walls or increase the depth of the wall cavity to accommodate the increased insulation requirements. Additionally, due to programs such as Passive House, Net Zero Energy Home challenges in several states, and highly incentivized, deep, energy-retrofit programs, high R-value wall assemblies and assemblies that employ a combination of insulation products are gaining popularity in the market.

Several builders have successfully used double-wall systems to achieve higher R-values in thicker, framed walls (Figure 1). In this context, a double wall consists of a load-bearing external frame wall usually constructed with $2 \times 4$ framing at 16 in. on center. This wall is built and sheathed as a typical exterior-frame wall. After the building is enclosed, an additional frame wall is constructed several inches inside the external load-bearing wall to provide the depth required to achieve the desired R-value.

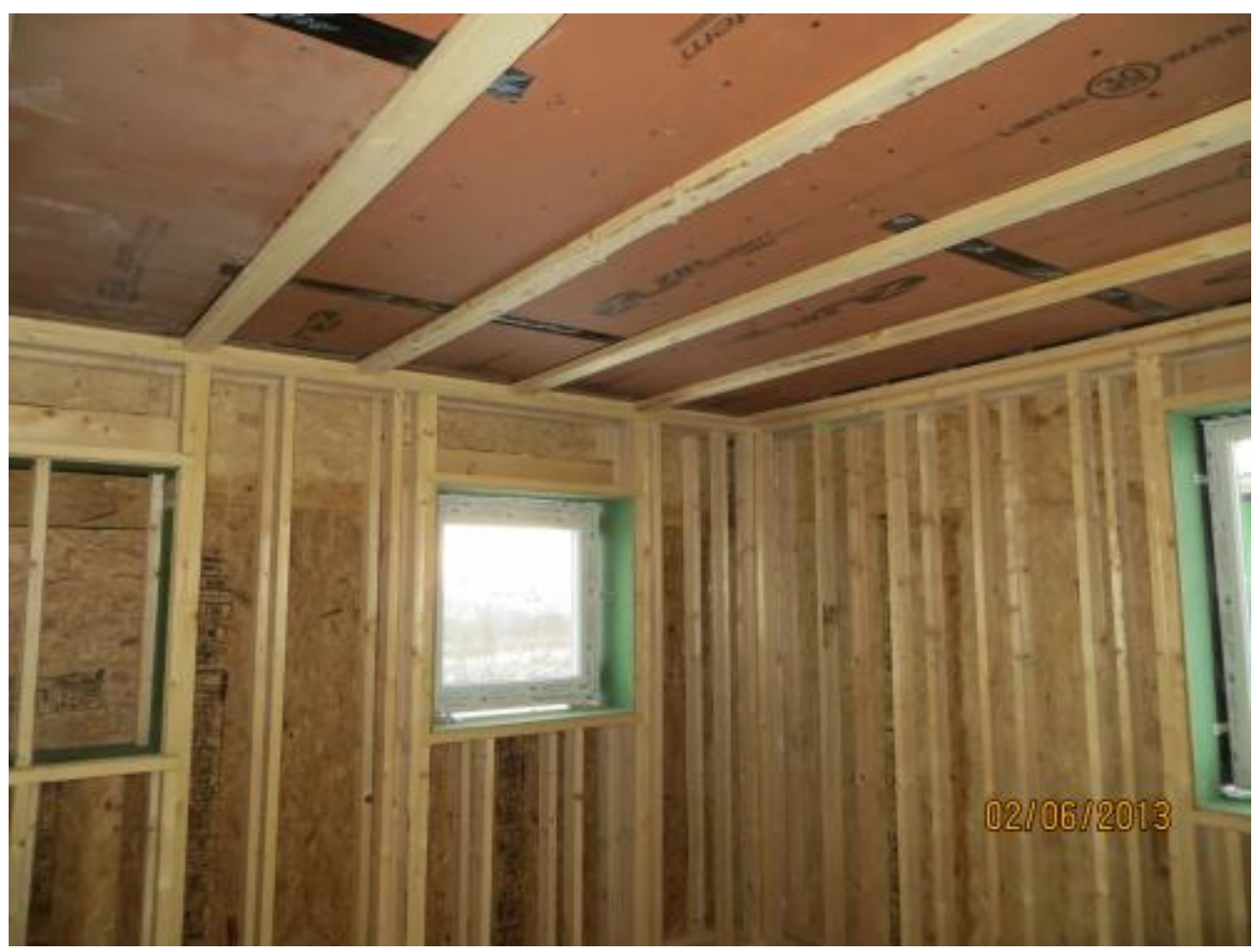

Figure 1. Double-wall construction

To builders of conventional stick-framed homes, often one of the most appealing features of double-wall systems is that there are very few new exterior details. Exterior sheathings, structural bracings, house wraps or building paper, and window and door flashings are usually identical to good details in conventional framed-wall systems. When transitioning from typical stick-frame construction to double walls, little to no additional training is needed, which allows 
framers and builders to save money and compete with others that are building different, more expensive, high R-value assemblies.

However, although the details in double-wall systems are very similar to those in conventional stick framing, there is sometimes less room for error. For example, several studies have confirmed colder temperatures of exterior sheathing, which can lead to increased chances for condensation from air exfiltration (Straube and Smegal 2009, Arena 2014, Ueno 2015). Depending on the temperature of the surfaces and the permeability of the materials, that moisture may get trapped inside of the walls, and it could potentially lead to mold growth and/or decay of the building materials. With the increased use of foam insulation, various vapor barrier applications, the drastic increase in retrofit activities, and the increasing thickness of the walls (all factors that can reduce the drying potential of the walls), moisture issues could become much bigger problems.

These guidelines have been created to help reduce the risk of moisture-related damage with a particular focus on assemblies that have no exterior rigid insulation installed over the exterior structural sheathing such as double walls, Larsen truss assemblies, and structural insulated panels. The recommendations are based on research conducted to date and current best practices. Recommendations are provided for appropriate cladding options, ratios of impermeable to permeable insulation, and vapor retarder levels and placement. 


\section{Decision-Making Criteria}

To increase the thermal performance of typical frame construction, one rather intuitive solution is to simply increase the thickness of the framing and thereby the insulation cavity. Although this is certainly an option, dimensional lumber for wall framing can be very expensive and difficult to work with. Engineered wall framing - such as I joists - are also an option, but these can be equally expensive and cumbersome.

Double walls offer a cost-competitive method of constructing high R-value walls, and they have already reached the commercialization stage. During the last five years, Steven Winter Associates, Inc., has consulted on several community-scale projects in the northeastern United States where double walls were the chosen construction method. That said, the following sections explore various cost and construction implications of using this framing method.

\subsection{Cost and Performance}

\subsubsection{Framing}

The additional labor to construct the second wall is one of the biggest costs related to doublewall construction. The additional framing requires approximately 4-5 person-days (32-40 personhours) for each 100 linear feet of double wall (Aldrich et. al. 2010). This is rather independent of wall height, but many corners, dormers, windows, and/or doors can substantially increase this value. Labor costs vary tremendously, but using an example framer's rate of $\$ 35$ per hour, the additional labor cost is $\$ 1,120$ - $\$ 1,400$ for each 100 linear feet of wall.

The amount of exterior framing lumber needed is doubled, but this is usually somewhat offset by the exterior wall being constructed of $2 \times 4$ framing rather than $2 \times 6$ (required to meet code in most cold climates), which is often significantly more expensive than $2 \times 4$ framing. Consequently, increased lumber costs for double walls are much less than increased labor costs. A survey of lumber suppliers in the Northeast showed that $2 \times 6$ framing is currently $50 \%$ more costly than $2 \times 4$ framing of the same quality and length. Example costs are shown in Table 1.

Table 1. Additional Lumber Costs for Double Walls per 100 Linear Feet

\begin{tabular}{c|c|c|c|c|c}
\hline & $\begin{array}{c}\text { Length of } \\
\text { 8-ft. Wall }\end{array}$ & $\begin{array}{c}\text { Framing } \\
\text { Factor }\end{array}$ & $\begin{array}{c}\text { Framing } \\
\text { Needed }\end{array}$ & $\begin{array}{c}\text { Framing Cost } \\
\text { per Foot }\end{array}$ & $\begin{array}{c}\text { Framing } \\
\text { Cost }\end{array}$ \\
\hline $\begin{array}{c}\text { Single 2 x 6 Wall } \\
\text { Double 2 x 4 } \\
\text { Wall }\end{array}$ & $100 \mathrm{ft}$. & $20 \%$ & $1,280 \mathrm{ft}$. & $\$ 0.61$ & $\$ 781$ \\
\multicolumn{1}{|r|}{} & $100 \mathrm{ft}$. & $20 \%$ & $2,560 \mathrm{ft}$. & $\$ 0.40$ & $\$ 1,024$ \\
\hline
\end{tabular}

Many of the framing-related costs - especially labor - can be managed by good building design and careful planning. Once familiar with the systems, there is not a substantial amount of additional time needed to design homes with double walls. It is important to note that these homes are usually very square and are designed for double walls. A conventional framed home with more corners and non-right angles requires substantially more framing time and material, so designers should be very conscious of the benefit of simple building footprints. 


\subsubsection{Insulation}

Insulation is the second largest cost of a double-wall system. The main cost element is the extra insulation itself; the extra time needed to install the insulation is secondary. From working with builders of 12-in. double walls with blown cellulose insulation, insulation costs increase 30\%$40 \%$ more than the cost of insulating a comparable $2 \times 6$ framed wall (Tauer 2009, Perkins 2009).

In the author's experience, dense-packed blown cellulose is the most common insulation used in these assemblies. Blown fiberglass is certainly an option, and open-cell spray polyurethane foam (ocSPF) can also be used to full depth. If using a combination of products, proper attention must be paid to the ratio of air-impermeable insulation (closed-cell spray polyurethane foam (ccSPF) to air-permeable insulation (fiberglass, cellulose) or condensation problems could occur. Figure 2 through Figure 4 show photographs of three different insulation strategies for a 12-in.-deep double wall.

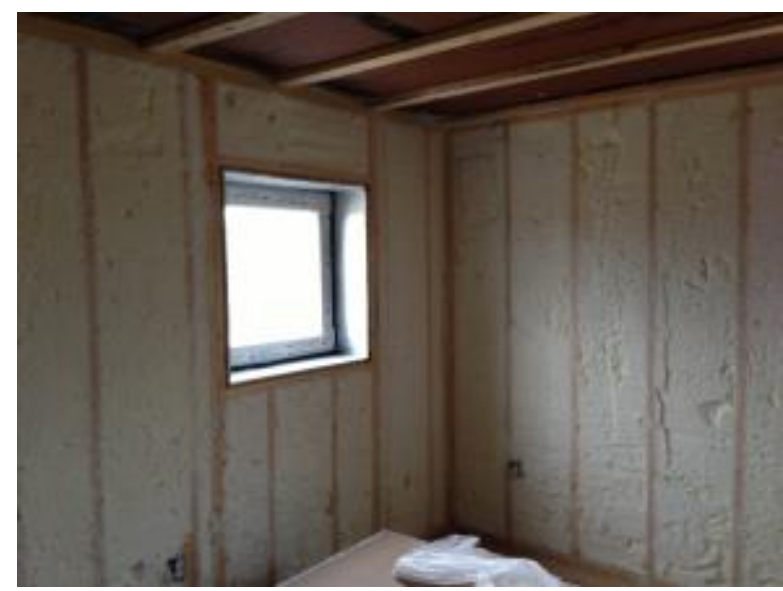

Figure 2. ocSPF in a 12-in. double wall

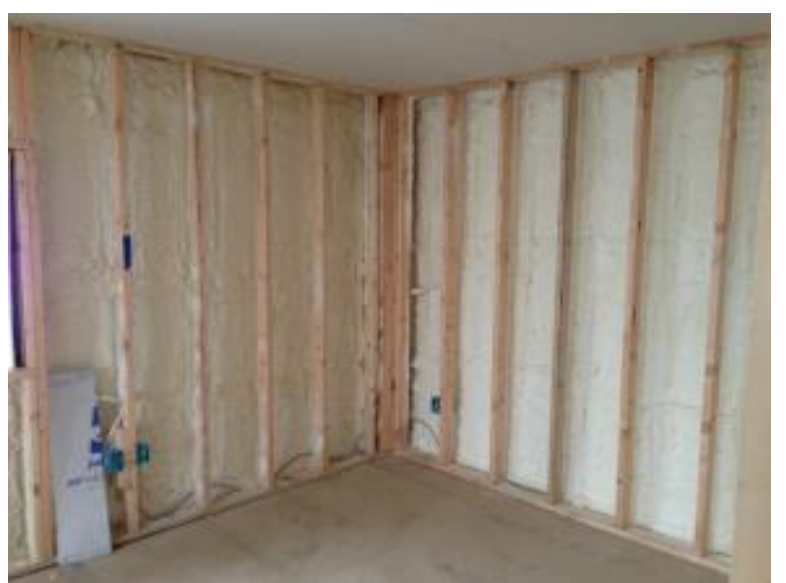

Figure 3. ccSPF in the outer stud cavity of a 12in. double wall. Cellulose will fill the remainder of the cavity.

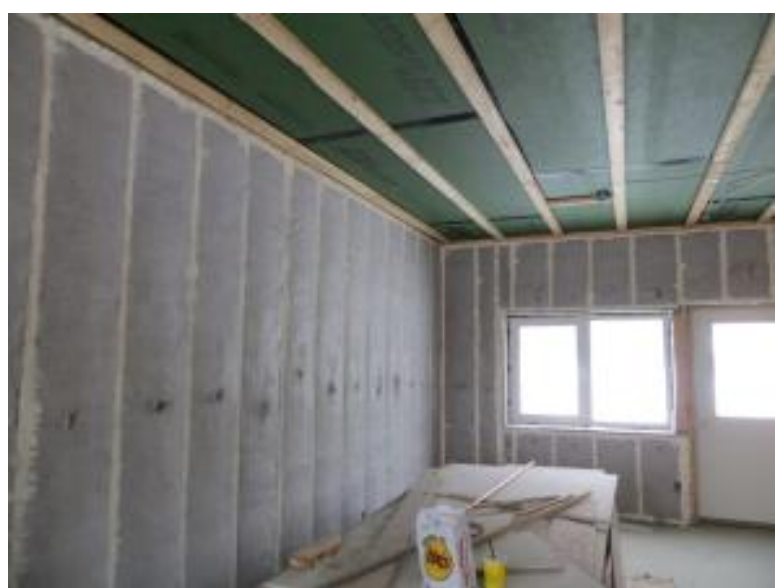

Figure 4. Full-depth cellulose insulation in a 12-in. double wall 
One noteworthy feature of the costs discussed above is that the additional framing labor is by far the largest component of the incremental costs, and this item is independent of wall thickness. Insulation cost, however, increases with wall thickness, and this is not a linear relationship because the labor costs to prepare for and install dense-packed cellulose do not change significantly as the wall gets thicker.

\subsection{Insulation Continuity}

Because double walls typically do not have exterior rigid insulation, the continuity of the insulation around the building shell must be carefully planned. The most critical intersections are the roof/wall connection and the slab/wall interface. If not detailed properly, thermal bypasses at these locations could result in condensation in the assemblies and potential moisture-related problems.

\subsubsection{Roof/Wall Connection}

The detail in Figure 5 shows full-depth ceiling insulation extending to the outer edge of the double wall, which results in a significant reduction in thermal bridging. Combined with an airtight enclosure, this detail reduces the chances for condensation and heat loss at the top plates. However, different roof pitches may not allow for full-depth insulation for the entire depth of the double-wall cavity, as shown in Figure 6. To prevent thermal bridging in this area, a higher Rvalue insulation can be used to spot treat the area and bring it to the full R-value of the ceiling insulation. In Figure 7, ccSPF was used only over the outer edge of the wall to increase the Rvalue in that location. Cellulose insulation was then used for the remainder of the ceiling once the height of the rafter was high enough to accommodate the full depth desired.

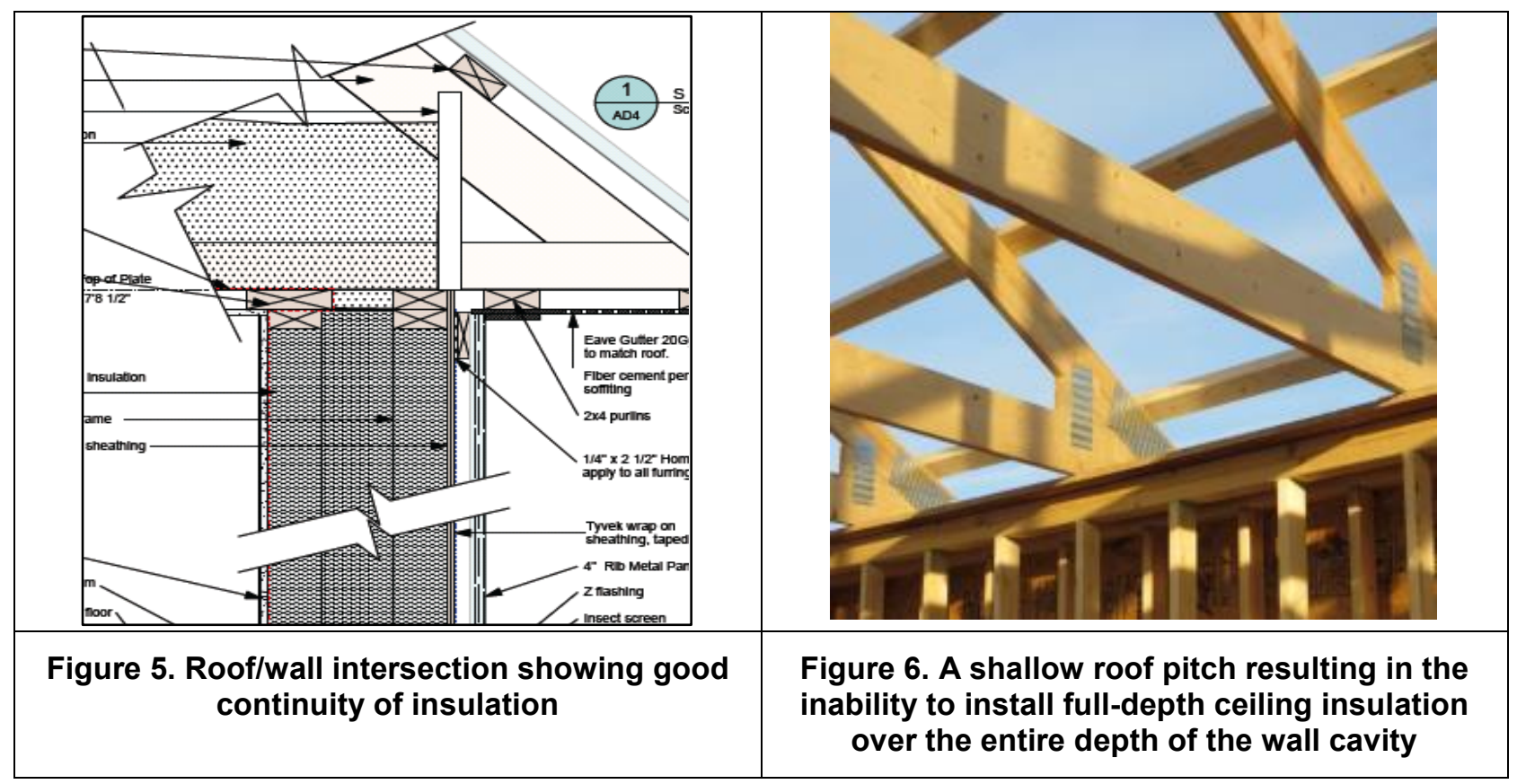




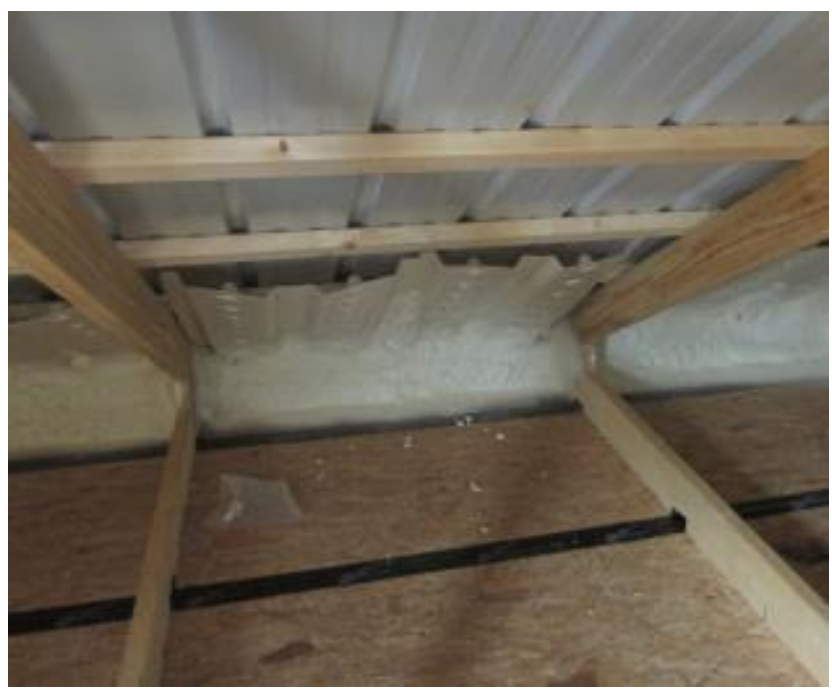

Figure 7. ccSPF installed over the outer edge of the double wall to the desired R-value for the ceiling

\subsubsection{Slab/Wall Intersections}

In projects where double walls are being considered, it is likely that the foundation will be well insulated as well. Incorporating the slab edge insulation or exterior basement insulation into the design can be another challenge facing the construction team when double-wall construction is being implemented. Because double-wall plates do not hang over the foundation (they are flush with the concrete edge), the foundation rigid insulation ends up proud of the wall plane, which leads to potential water-management issues and thermal bypasses at the wall bottom plates. To accommodate this situation, the insulation should extend upward past the bottom plates and then be properly incorporated into the drainage plane. The detail in Figure 8 shows an example of how one project team incorporated the slab edge into a weather barrier impregnated on oriented strand board. 

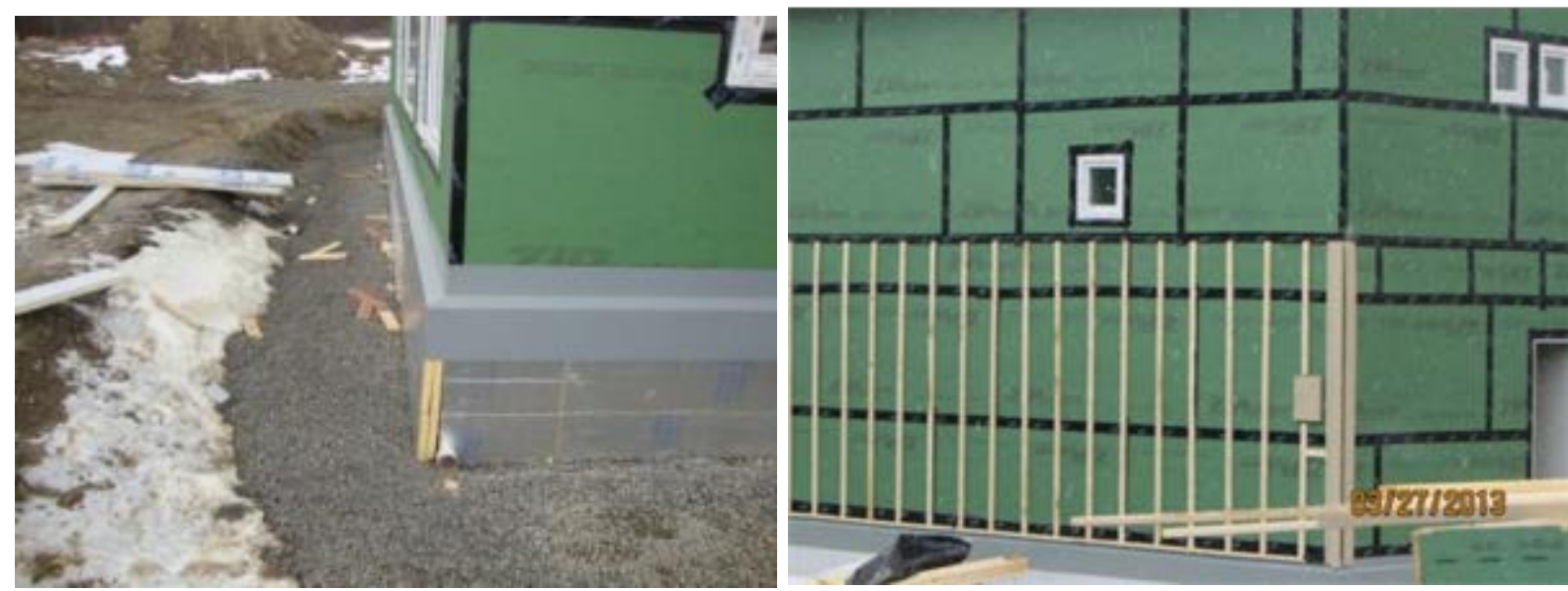

Figure 8. Flashing over slab edge insulation was taped to the sheathing using the manufacturer's approved tape. The vented cladding was then attached with $3 / 4$-in. furring strips, and it overlapped the flashing.

\subsection{Durability and Moisture Issues}

Both modeling and field studies have shown that temperatures of the exterior sheathing of walls without exterior rigid insulation are prone to increased chances for condensation from air exfiltration (Straube and Smegal 2009, Arena 2011, Arena 2014, Ueno 2015). The key steps to ensuring long-term durability of these types of wall structures include the following:

- Ensure that the moisture content of the building materials remains $<12 \%$ during construction.

- Implement meticulous air sealing.

- Install adequate mechanical ventilation to manage indoor relative humidity levels.

- Install a robust weather-resistant barrier.

- Provide a vented cladding system.

Because high R-value walls rely on drying to the interior as well as the exterior, an interior vapor barrier is generally not recommended. There are acceptable conditions under which elimination of the vapor barrier is allowed in the 2012 International Residential Code (IRC). Table R702.7.1 in the 2012 IRC (reproduced in Table 2) lists the acceptable circumstance when a Class III vapor retarder (also called a latex paint) can be used. For marine Climate Zone 4 through Climate Zone 6 , a Class III vapor retarder may be used if either a vented cladding is installed or the minimum level of insulating sheathing is installed. The insulating-sheathing requirement may be met by using the same R-value of 2-lb ccSPF on the interior side of the exterior sheathing. If interiorcavity 2-lb ccSPF is used in a hybrid high R-value wall, a vented cladding is still highly recommended. 
Table 2. 2012 IRC Requirements for Walls with a Class III Vapor Retarder

\begin{tabular}{|c|c|}
\hline Climate Zone & $\begin{array}{c}\text { IRC } 2012 \\
\text { Table R702.7.1 (Not Listed) }\end{array}$ \\
\hline Marine 4 & $\begin{array}{l}\text { Vented cladding } \\
\text { - Wood sheathing product (oriented } \\
\text { strand board or plywood) } \\
\text { - Fiber board or } \\
\text { - Gypsum } \\
\text { Insulating sheathing } \\
\qquad>=\mathrm{R} 2.5 \text { for } 2 \times 4 \\
\text { - }>=\mathrm{R} 3.75 \text { for } 2 \times 6\end{array}$ \\
\hline 5 & $\begin{array}{l}\text { Vented cladding } \\
\text { - Wood sheathing product (oriented } \\
\text { strand board or plywood) } \\
\text { - Fiber board or } \\
\text { - Gypsum } \\
\text { Insulating sheathing } \\
\qquad>=\text { R5 for } 2 \times 4 \\
\text { - }>=\text { R7.5 for } 2 \times 6\end{array}$ \\
\hline 6 & $\begin{array}{l}\text { Vented cladding } \\
-\quad \text { Fiber board or } \\
-\quad \text { Gypsum } \\
\text { Insulating sheathing } \\
\qquad>=\text { R7.5 for } 2 \times 4 \\
->=\text { R11.25 for } 2 \times 6\end{array}$ \\
\hline 7 & $\begin{array}{l}\text { Insulating sheathing } \\
\begin{array}{r}->=\mathrm{R} 10 \text { for } 2 \times 4 \\
-\quad>=\mathrm{R} 15 \text { for } 2 \times 6\end{array}\end{array}$ \\
\hline
\end{tabular}

If specifically required to install an interior Class I or Class II vapor retarder by your building department, consult an expert to perform a hygrothermal analysis, and make recommendations to the building officials based on that report. Insulation manufacturers often have recommendations for the types and placement of vapor retarders for their specific material, and they have been known to provide letters to the code officials to that effect if the code is in conflict with their recommendations. If absolutely necessary, chose a "smart" vapor retarder that becomes more vapor open as the relative humidity in the wall increases. These products are specifically designed to let the walls dry if they do get wet.

\subsection{Minimizing Disturbances of Insulation}

When an entire story of a home has a single 9-in. x 12-in. wall cavity filled with insulation, adding or repairing penetrations after the walls are insulated can seriously disrupt the insulation. In double-wall homes, careful planning for these penetrations is important, and all trades should be aware of the special requirements of the wall system. Because there are not discrete stud bays filled with insulation, it is good practice to install insulation netting or blocking around critical 
wall penetrations. In this way, if a vent pipe must be accessed or repaired for any reason, insulation in the entire wall is not compromised; only insulation around the penetration must be replaced (see Figure 9).

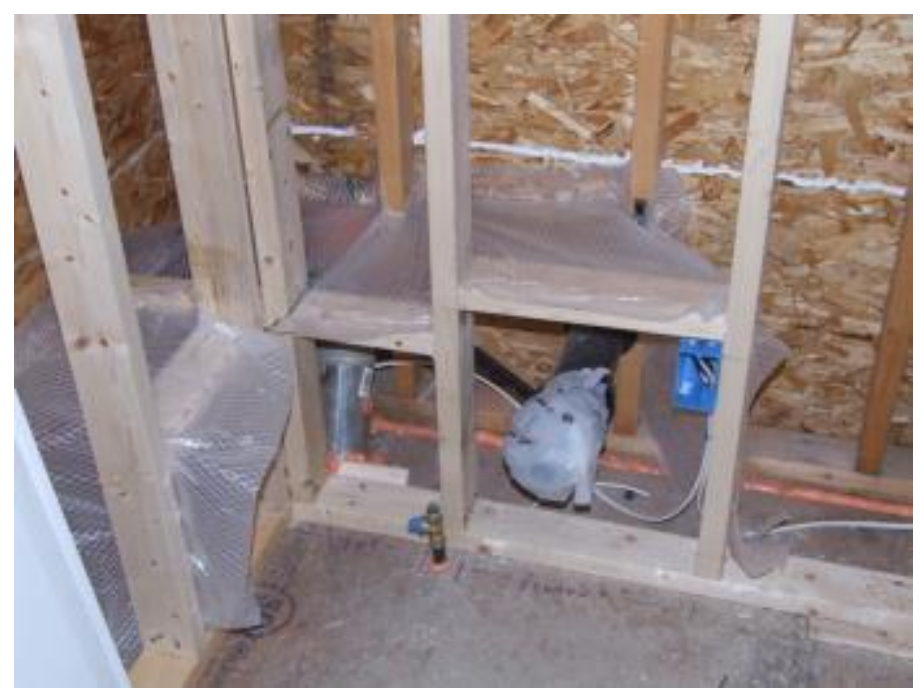

Figure 9. Insulation netting surrounds vents and plumbing penetrations in an exterior double wall. 


\section{Technical Description}

\subsection{Applicable Wall Systems}

As mentioned earlier, these guidelines have been created to help reduce the risk of moisturerelated damage with a particular focus on high R-value assemblies with no exterior rigid insulation installed over the exterior structural sheathing. Such assemblies include double-wall assemblies, Larsen trusses, and structural insulated panels. Although this guide focuses on double-wall framing, considerations and recommendations for moisture control, air sealing, and insulation apply to all wall assemblies without exterior rigid insulation.

\subsection{Double-Wall Framing}

A double wall consists of a load-bearing external frame wall usually constructed with $2 \times 4$ framing at 16 in. on center. This wall is built and sheathed as a typical exterior frame wall. After the building is enclosed, an additional frame wall is constructed several inches inside the external load-bearing wall.

This second wall can be constructed when interior framing begins, and it can be constructed of 2 x 4 or $2 \times 3$ framing at 16 in. or 24 in. on center. Although $2 \times 3$ framing is often proposed for cost savings, it is challenging to find $2 \times 3$ lumber that is consistently square and straight.

Because of this, most builders tend to use $2 \times 4$ framing for both the exterior and interior walls.

Although studies have shown that typical framing factors in homes (with studs at 16 in. on center) are near 25\% (Carpenter 2003), with efficient framing techniques this framing factor can rather easily be reduced to $20 \%$. Even lower framing factors are possible when moving to 24 -in. stud spacing.

Figure 10 through Figure 12 show examples of advanced framing techniques. Two-stud corners are very simple to implement on both the outer and inner framed wall because no drywall is attached to the outer wall, and no exterior sheathing is attached to the inner wall (Figure 10).

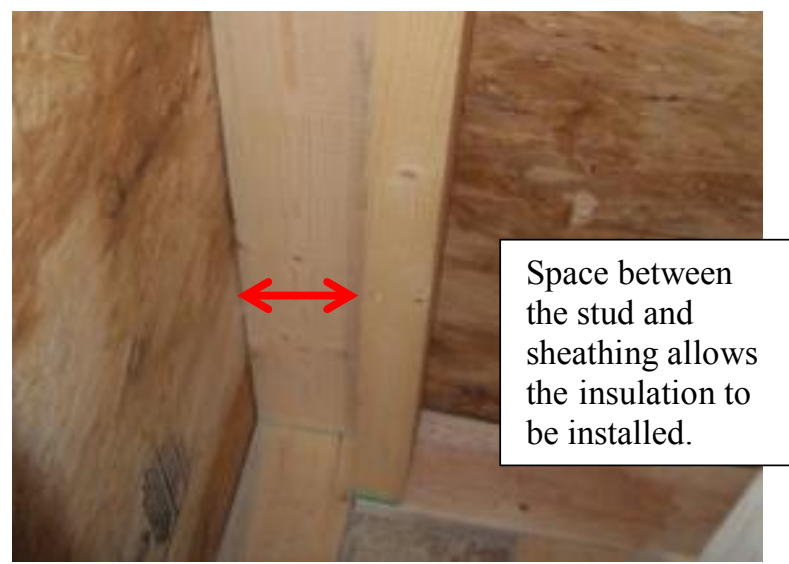

Figure 10. Two-stud corners can be used for both the interior and exterior walls in the double-wall assembly.

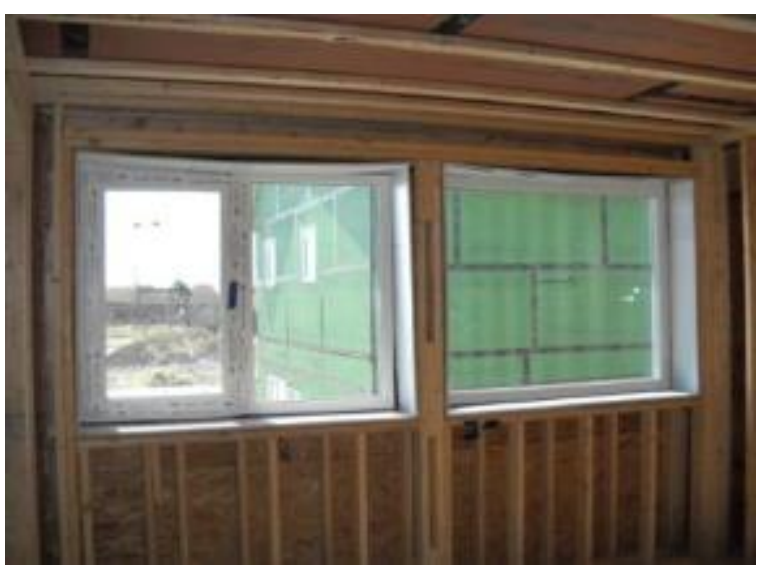

Figure 11. Reduced framing around windows on the interior wall

Figure 11 and Figure 12 demonstrate reduced framing at the window and door openings that results in increased wall insulation. On the inner wall, double top plates and jack studs are often 
not necessary (though jack studs may still be used for more consistent alignment of window openings). Finally, ladder framing can be used to attach interior partition walls to exterior walls to further reducing framing.

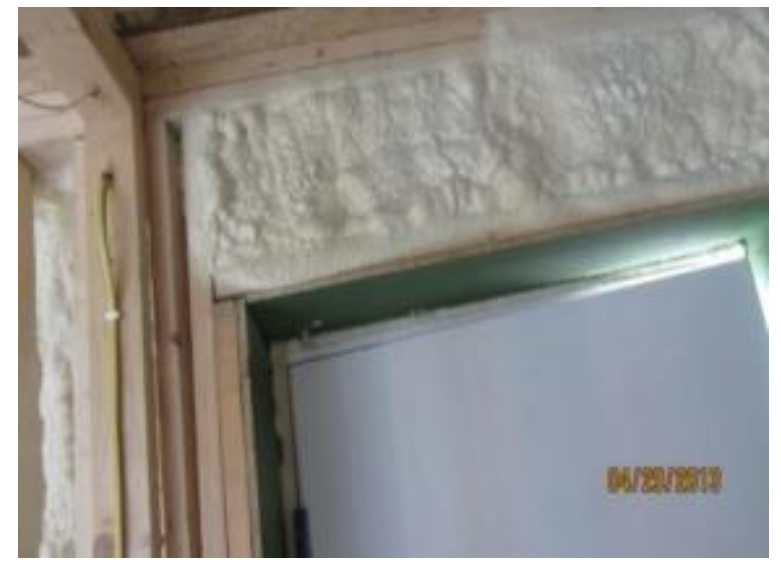

Figure 12. Reductions in framing around the openings allows for more insulation in headers.

Such advanced framing strategies are encouraged because they can certainly save framing material and labor, but because of the thermal break between the two walls, reducing the framing does not dramatically increase the thermal resistance of the wall system (see Table 3).

Additionally, because of the substantial thermal break between the walls, there is also very little thermal impact when the inner and outer studs are aligned compared to staggered-stud configurations.

Table 3. Thermal Effects of Framing Factors on Double Walls

\begin{tabular}{c|c}
\hline Framing Factor & $\begin{array}{c}\text { Whole-Wall R-Value } \\
\left(\mathbf{f t}^{\mathbf{2}} \mathbf{h}{ }^{\circ} \mathbf{F} / \mathbf{B t u}\right)\end{array}$ \\
\hline $16 \%$ & 35 \\
$20 \%$ & 34 \\
$25 \%$ & 33 \\
\hline
\end{tabular}

Before the windows and doors are set, the rough openings must be boxed out with sheathing, lumber, or drywall, as shown in Figure 13, to provide blocking between the two walls for the insulation that will typically be blown or sprayed into the wall cavity. Sloping the window sill toward the exterior or providing a window dam on the interior side of the window to prevent water intrusion is highly recommended. 


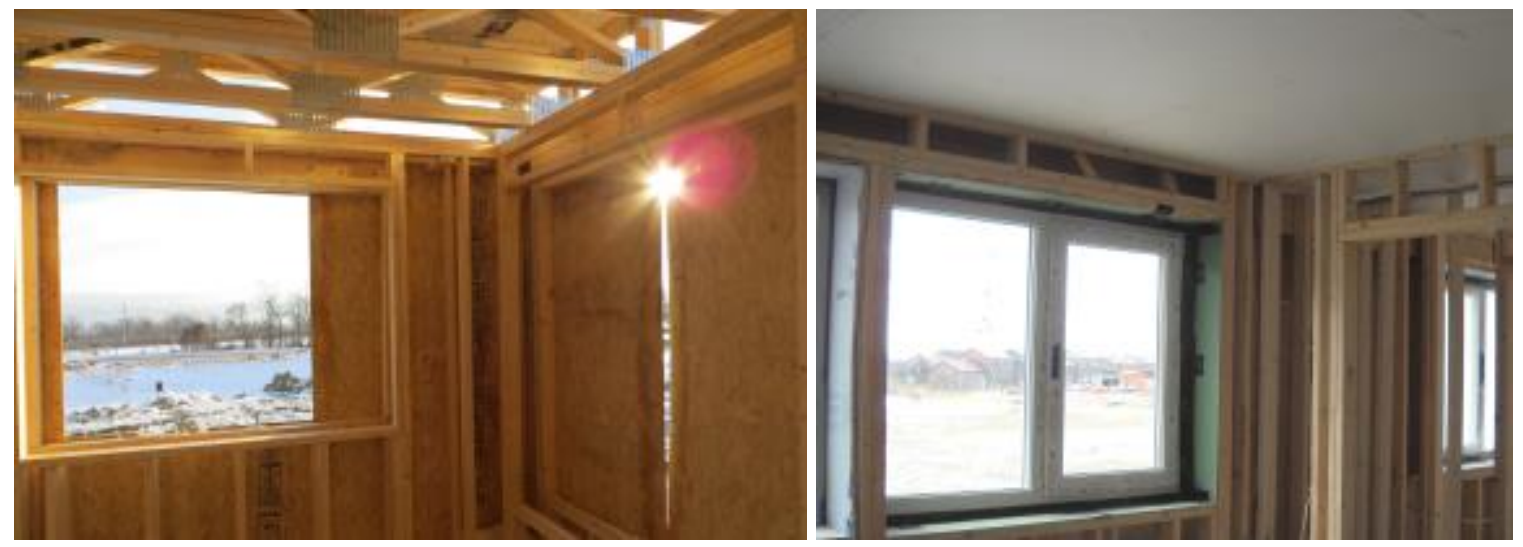

Figure 13. Windows in double walls: (left) a framed window opening and (right) a set window

\subsection{Electrical and Plumbing}

Electrical rough-in in double walls can be slightly simplified because the wires can be run between the two framed walls making drilling unnecessary. Electrical boxes are normally installed on the interior wall. Plumbing and mechanical penetrations through the exterior walls should be blocked off or netted before the insulation is installed to minimize disturbance to the insulation if repairs or service are needed at these locations in the future.

\subsection{Air Barriers}

As with any high-performance wall system, air sealing is critical. Before insulating, meticulous caulking and/or foaming of the exterior sheathing, top and bottom plates, penetrations, etc., is strongly advised. Interior or exterior air barriers (Figure 14 and Figure 15) are acceptable, and each has pros and cons.

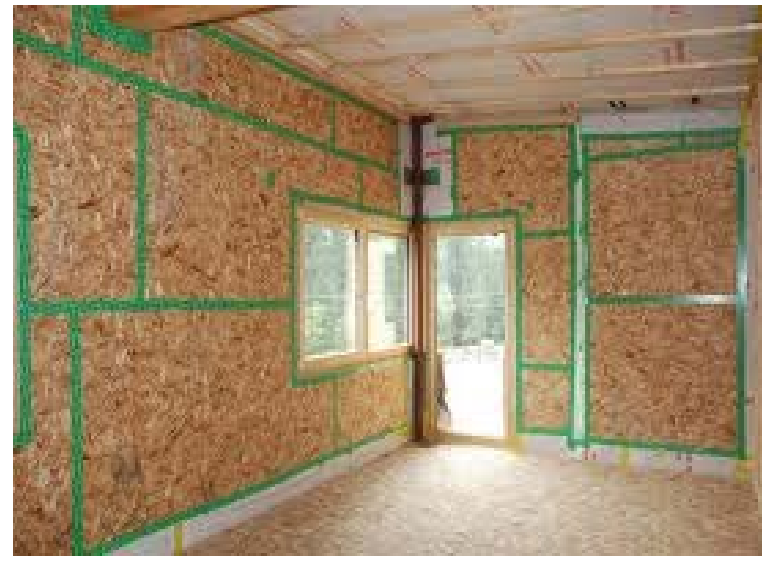

Figure 14. Interior air barrier with all seams taped

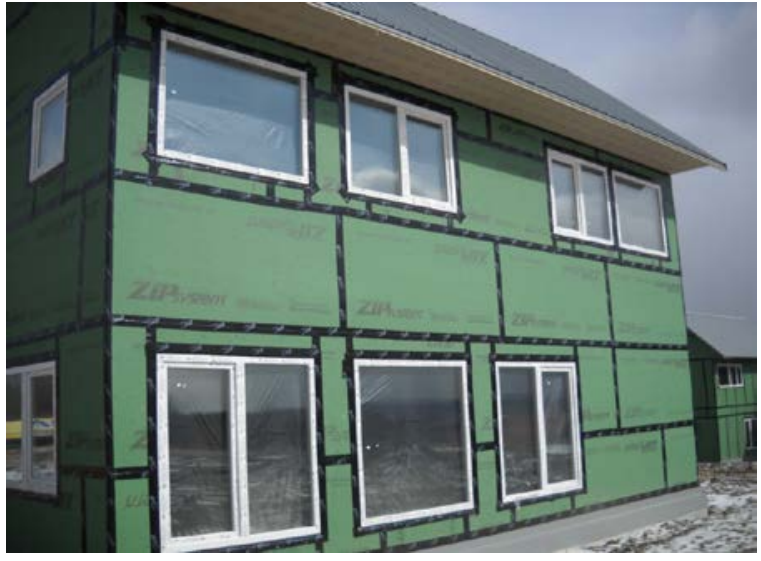

Figure 15. Exterior air barrier with all seams taped

\subsubsection{Interior Air Barriers}

As shown in Figure 14, the interior surface of the wall can be used as the airtight layer in a double-wall home. However, because the electrical boxes and some plumbing vents run in the exterior walls, creating a significantly airtight barrier can be difficult. A typical approach is to 
install a sheathing product on the interior of the double wall and then fur out a small chase wall where the electrical and plumbing runs can be housed without actually penetrating the air barrier. The pros and cons of this approach include:

- Pros

- It is easy to connect the wall airtight layer to the ceiling airtight layer.

- There is no need to test the airtight layer twice; only once after the insulation is sufficient to ensure goals have been met.

- This approach prevents convective looping if high and low air leaks are present on the interior of the envelope.

- Cons

- It is more difficult to tie in the airtight layer of the foundation.

$\circ$ There is an additional cost of the second layer of sheathing and additional labor to install the interior chase wall.

\subsubsection{Exterior Air Barriers}

One method for implementing an exterior airtight layer is shown in Figure 15. Tape is used to seal all seams and corners in the structural sheathing whether it is oriented strand board, plywood, or an impregnated weather-resistant barrier. Sheet weather barriers applied on top of the structural sheathing can also act as the air barrier and will need to be taped and incorporated in the rest of the airtight layer in the same way as the sheathing. All connections to the window and door openings must be taped, all penetrations must be sealed, and the sheathing must be tied in to the ceiling and foundation air barriers. Pros and cons of this method include:

- Pros

O It is easy to connect the wall airtight layer to the foundation airtight layer.

O It is easy to inspect, and there are fewer jogs in the airtight layer.

- There is no extra cost for an interior chase wall; the interior is simply netted for cellulose, and all electrical and plumbing penetrations are handled normally.

- Cons

- It is more difficult to tie in the airtight layer of the ceiling.

$\circ$ Using sheet weather barriers as the airtight layer can be more labor intensive than using the structural sheathing.

- The airtight layer should be tested twice, once the air barrier is in place before the insulation is installed and once after the insulation but before the drywall.

\subsection{Insulation}

After rough-in and air sealing, the wall cavities can be filled with insulation.

\subsubsection{Single Insulation Strategy}

Full-depth cellulose, fiberglass, or ocSPF can be used to fill the entire wall. When installing cellulose or fiberglass, insulation netting or a reinforced vapor retarder (when a vapor retarder is 
required) is usually installed on the inside of the interior framing. Aside from the added insulation material, the time to install the blown insulation is slightly higher. However, the considerable preparation time (primarily installing netting for blown insulation) is very similar to time required when blowing a conventional framed wall. For example, the additional time needed to insulate $800 \mathrm{ft}^{2}$ of a 12-in. double wall with dense-blown cellulose (when compared to insulating a single $2 \times 6$ wall with blown cellulose) is approximately two person-hours. The total incremental cost is approximately $30 \%$; additional insulation material accounts for most of this cost (Tauer 2009, Perkins 2009).

The method of blowing insulation is somewhat different than it is in single-frame construction. Because the wall is not divided into discrete stud bays, the exterior walls for each story basically include one large insulation cavity. When using dry, dense-blown insulation, insulators typically fill this cavity by moving around the home in a circular pattern; each section of the wall is partially filled. After the walls are nearly completely filled, the insulator makes one more circuit around the home blowing through each interior stud bay until the insulation reaches the desired density (Tauer 2009).
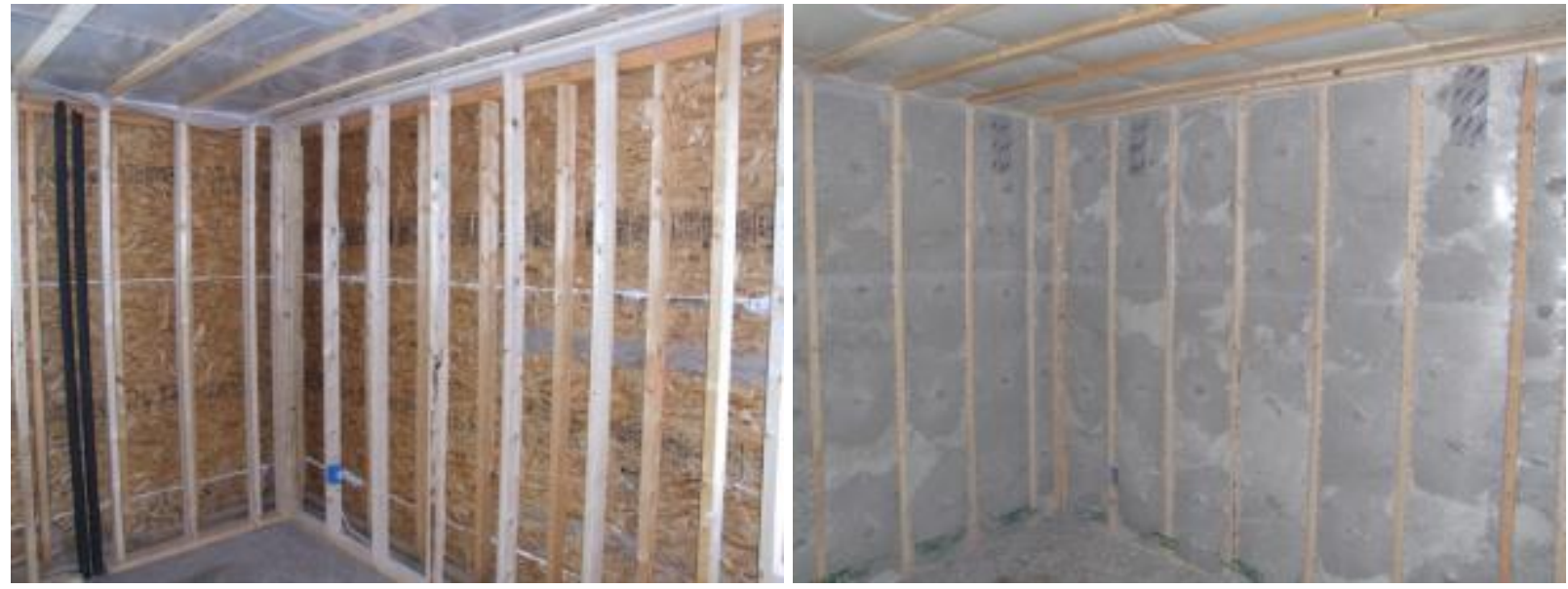

Figure 16. Double wall before and after insulation with dense-blown cellulose

As noted, ocSPF can also be used in the entire cavity. The cost of the material is generally higher, but there is a trade-off because no netting is required, and the entire cavity can be filled immediately without making circular passes around the home. This labor savings can make this method of insulation cost-competitive with loose-fill insulation.

Because the gap between the two walls is filled completely with insulation, there is no thermal bridge through the wall system. This is shown in Table 4, and this thermal break results in whole-wall R-values very close to nominal R-values. 
Table 4. R-Values for Double Walls of Varying Thicknesses

\begin{tabular}{c|c|c|c}
\hline \multirow{2}{*}{$\begin{array}{c}\text { Space Between } \\
\mathbf{2} \mathbf{4} \mathbf{4} \text { Walls }\end{array}$} & $\begin{array}{c}\text { Total } \\
\text { Insulation } \\
\text { Depth }\end{array}$ & Nominal & R-Values* $\left(\mathbf{f t}^{2}{ }^{\circ} \mathbf{F} \mathbf{h r} /\right.$ Btu $)$ \\
\cline { 3 - 4 } & 8 in. & 30 & Whole-Wall \\
\hline $\mathbf{1}$ in. & 9 in. & 33 & 30 \\
\hline $\mathbf{~ i n . ~}$ & 10 in. & 37 & 34 \\
\hline in. & 12 in. & 44 & 42 \\
\hline
\end{tabular}

* Values are based on R-3.7 per inch of dense-packed cellulose insulation.

\subsubsection{Hybrid Insulation Strategy}

A common option when combining insulation products is ccSPF. Not only does it have a higher $\mathrm{R}$-value/inch compared to other insulation types, it also provides a vapor retarder. This hybrid insulation strategy can be useful when floor space is at a premium and wall thickness cannot be increased but a higher wall R-value is desired. If using a combination of products, proper attention must be paid to the ratio of air-impermeable insulation (ccSPF) to air-permeable insulation (fiberglass, cellulose, ocSPF) or condensation problems could occur. Refer to Table R702.7.1 in the 2012 IRC to determine the proper ratio. Divide the required wall R-value for your climate zone by the minimum R-value of the insulating sheathing to determine the ratio of impermeable to permeable insulation. Multiply the desired R-value for the high R-value wall by this ratio, and divide by the R-value per inch of the impermeable insulation. This will tell you how many inches of impermeable insulation you will need for your assembly. 
Example: Determine (1) the minimum thickness of the air-impermeable insulation for a double wall in Climate Zone 6 that will be insulated with cellulose and ccSPF, (2) the thickness of the cellulose, and (3) the total thickness of the wall. The desired R-value of the assembly is R-50 minimum.

$$
\begin{aligned}
& \mathrm{ccSPF} \approx \mathrm{R}-6.5 / \mathrm{in} . \\
& \text { cellulose } \approx 3.6 / \mathrm{in} .
\end{aligned}
$$

\section{Answer 1: ccSPF thickness}

Step 1. Determine the proper ratio of impermeable insulation needed.

Table 702.7.1 states that a minimum R-value of $7.5 \mathrm{ft}^{2} \cdot{ }^{\circ} \mathrm{F} \cdot \mathrm{hr} / \mathrm{Btu}$ is required for a $2 \times 4$ wall. The total R-value requirement for a $2 \times 4$ in that climate is R-21. Therefore, the ratio of impermeable ccSPF to permeable cellulose would be

$$
\mathrm{R}-7.5 \div \mathrm{R}-21=36 \% \text {. }
$$

Step 2. Determine the minimum R-value of ccSPF needed in an R-50 assembly in Climate Zone 6.

$$
\mathrm{R}-50 \times 0.36=\mathrm{R}-18
$$

Step 3. Determine the number of inches of ccSPF needed in an R-50 assembly in Climate Zone 6

$$
\mathrm{R}-18 \div \mathrm{R}-6.5 / \text { in. }=2.8 \text {. A 3-in. minimum should be specified. }
$$

\section{Answer 2: Cellulose thickness}

Step 1. Determine the remaining R-value needed.

$$
\mathrm{R}-50-\mathrm{R}-18=\mathrm{R}-32 \text { needed }
$$

Step 2. Determine the thickness of the cellulose

$$
\mathrm{R}-32 \div 3.6 / \text { in. }=8.8,9 \text { in. of cellulose needed. }
$$

\section{Answer 3: Total wall thickness}

3 in. of ccSPF +9 in. of cellulose $=\underline{12 \text {-in. wall depth }}$

Space between the two walls $=12$ in. $-(2 \times 3.5$-in.studs $)=$ 5-in. gap needed .

\subsection{Moisture-Management System}

Because high R-value walls dry more slowly than conventional construction, attention to the moisture management of the façade is even more critical. Wood components must be properly separated from the masonry and protected from bulk water leaks by a robust weather- 
management system. Avenues for drying through-vented claddings must also be provided in case water does make its way into the assembly. Finally, preventing warm, moist air from entering the façade must be accomplished through diligent air sealing and by controlling interior moisture levels.

\subsubsection{Capillary Breaks}

A capillary break should be installed between the concrete foundation and the wall components for the entire depth of the wall to prevent foundation moisture from being wicked up by the building materials. Figure 17 shows an incomplete capillary break that was installed only under the exterior bearing wall's bottom plate. The break should span the entire depth of the wall so that both walls and the insulation will be separated from the concrete.

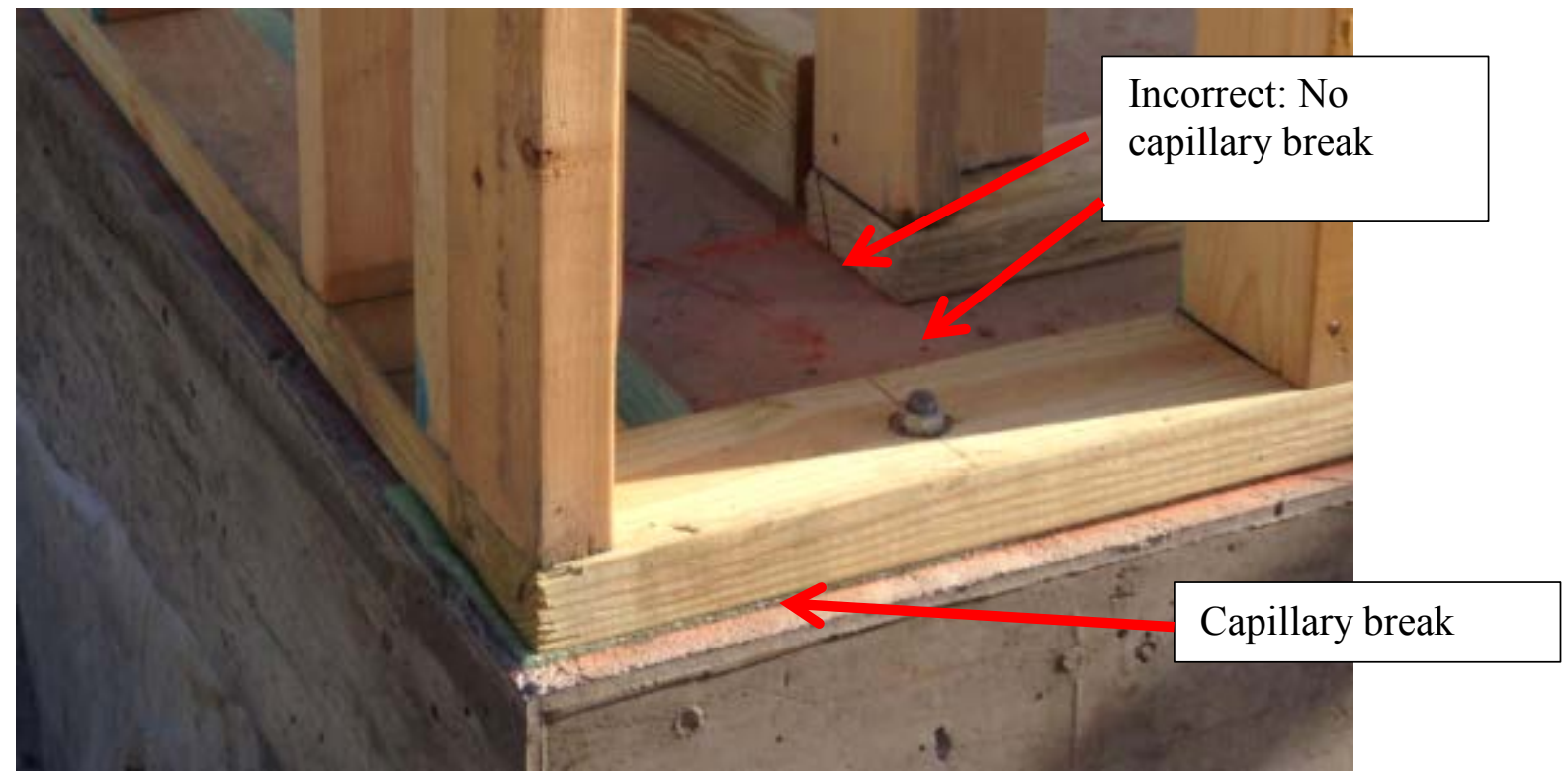

Figure 17. Incomplete capillary break. It should be installed the entire depth of the wall to keep lumber and insulation from wicking up moisture.

\subsubsection{Water-Resistive Barriers}

The water-resistive barrier (WRB) for a double-stud wall is no different than that for conventional framing. The options include building wraps, liquid-applied membranes, and impregnated sheathings (see Figure 15 under the Air Barriers section) that come from the factory with the WRB applied directly to the structural sheathing. However, attention to detail is far more critical because high R-value assemblies dry more slowly than standard construction. Bulk water leaks could result in much more damage in a high $\mathrm{R}$-value wall because the materials could remain wet for longer periods of time, which increases the potential for mold growth and decay. No matter which method is used, the installation must be robust, and the product should be vapor open to allow for drying to the exterior. Products greater than 10 perms are recommended by the author. 


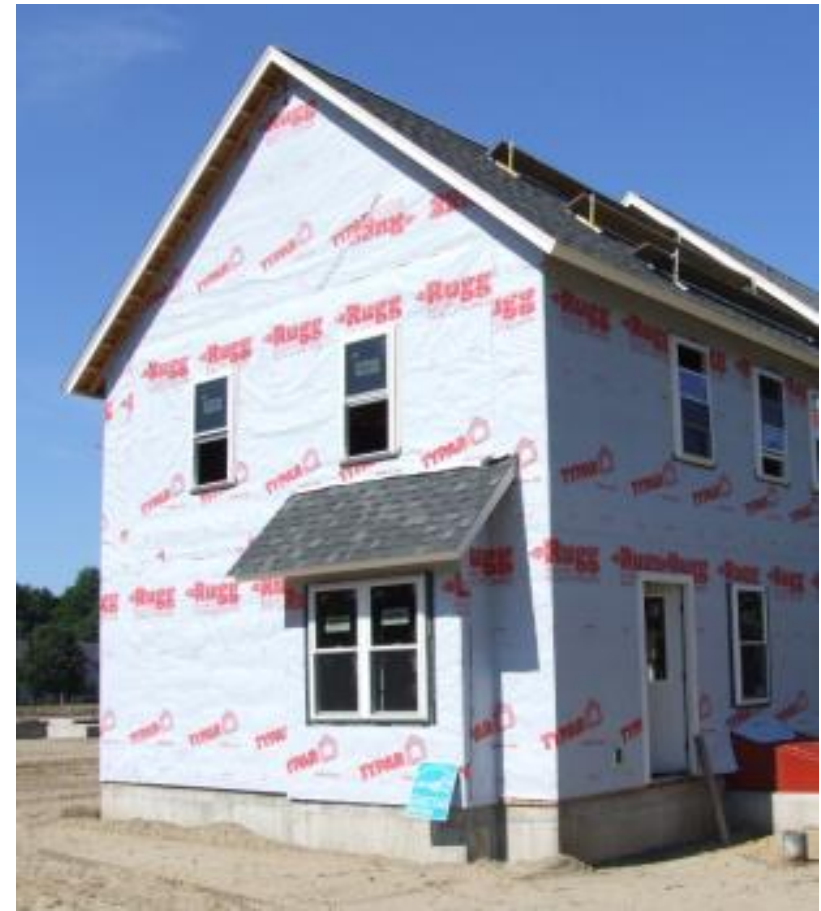

Figure 18. Example of a building wrap being used for the WRB

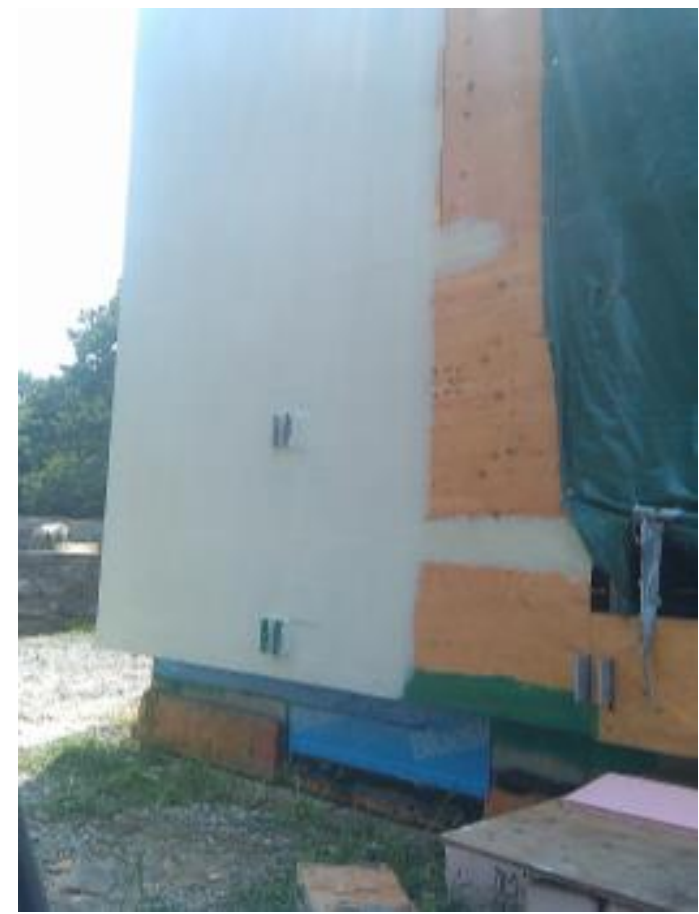

Figure 19. Image of liquid-applied WRB

\subsubsection{Cladding}

To aid in drying the assembly, particularly the exterior sheathing, a ventilated cladding is highly recommended. Figure 20 and Figure 21 show examples of attachments for two different types of siding: horizontal fiber cement boards and corrugated metal panels. A ventilated cladding system, also often referred to as a rain screen, in conjunction with vapor-open materials on both the interior and exterior of the wall assembly, result in the best drying potential for high R-value walls without exterior rigid insulation. 


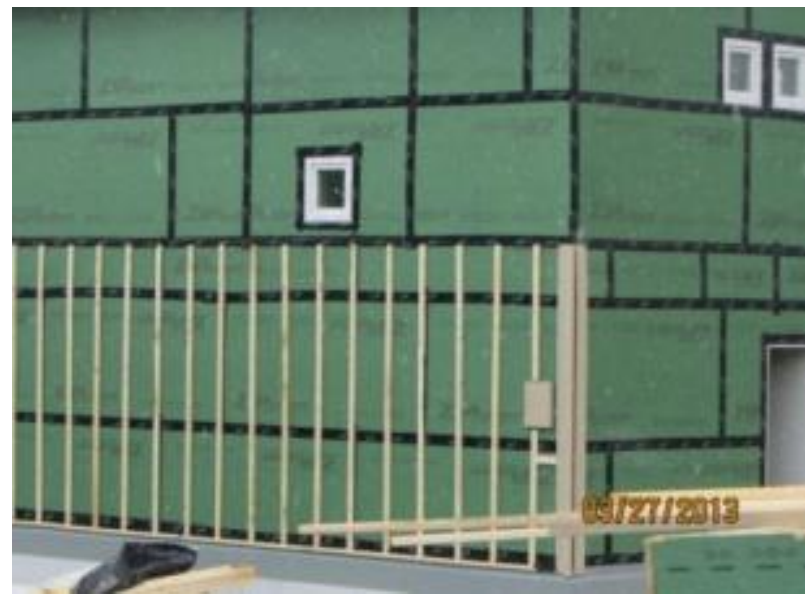

Figure 20. Vertical furring strips create a vent space for horizontal fiber cement siding.

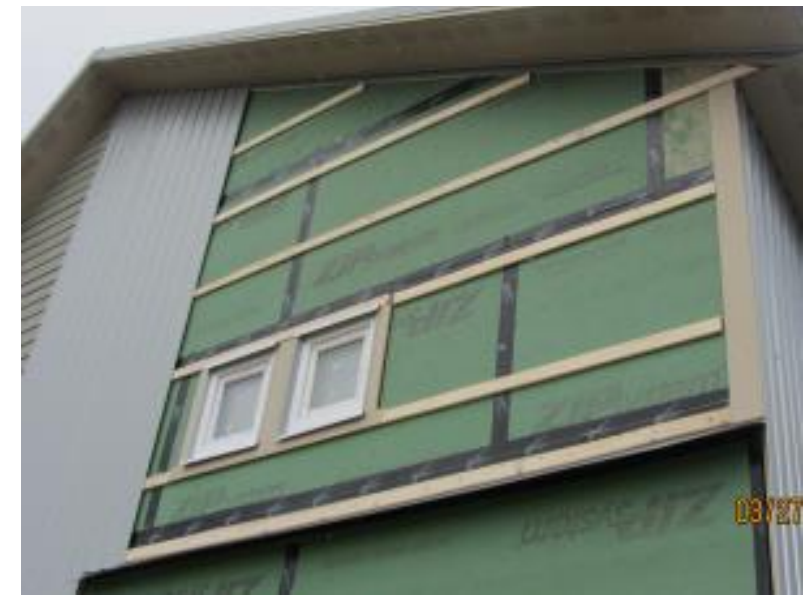

Figure 21. Horizontal furring was used to attach a corrugated metal panel siding that allows vertical draining and venting of the sheathing.

\subsubsection{Mechanical Ventilation}

The durability of high R-value walls is highly dependent on controlling the exfiltration of the interior air through the building envelope as well as controlling the moisture inside the building. If the interior air can enter the wall cavity, the potential for condensation on the colder surfaces on the interior of the wall assembly increases as the moisture levels in the home increase. Control of the interior air moisture levels must be achieved through proper ventilation. The level of ventilation will depend on the number of occupants, pets, plants, and other sources of moisture in the home.

Continuous mechanical ventilation should be installed in every high-performance home. In cold climates, heat- or energy-recovery ventilation is recommended to reduce energy use and to ensure that air entering the home does not create cold spots and discomfort. Methods to reduce fan noise from the ventilation system should also be employed as should techniques for reducing vibration noise. The goal is to minimize the chances that the system will be turned off due to comfort or noise issues.

A method to increase the continuous ventilation level should also be provided so that the occupants can remove unusually high levels of moisture as needed. These instances may result from cooking, bathing, an unusually high number of occupants, etc. Manual boost controls or humidity sensors can be used. Regardless of how this is achieved, indoor relative humidity levels during the winter months should be kept between $30 \%$ and $40 \%$. 


\section{Measure Implementation}

\subsection{Climate-Specific Factors}

This guide is intended for use in Climate Zones 5 and higher. Cold climates that also experience hot-humid summers are the primary targets because they are less forgiving than cold-dry climates with respect to drying the high R-value assemblies. However, the information contained here is still applicable but not as critical.

\subsection{Field Inspection}

To ensure that assemblies are constructed in a durable manner, pre-insulation air-leakage testing, pre-drywall insulation inspections, and pre-drywall air-leakage testing are highly recommended. Preventing exfiltration of the interior air into the wall assembly during the cold months is crucial for moisture control.

\subsection{Install Procedure}

Following is a sequential layout of the steps required to build an airtight, water-managed, high $\mathrm{R}$-value wall assembly using double-wall construction. Details for all typical junctions have been provided. This guide assumes that all components of the building envelope are high performance and super insulated. 


\subsection{Foundation Details}

Double-wall construction can be used independent of the foundation type chosen. Details for basement, crawl space, and slab-on-grade applications are provided below. Proper placement of the vapor-control layer and alignment of the foundation insulation are the critical steps at this stage. The red dashed line indicates the combined air/water-resistive barrier.

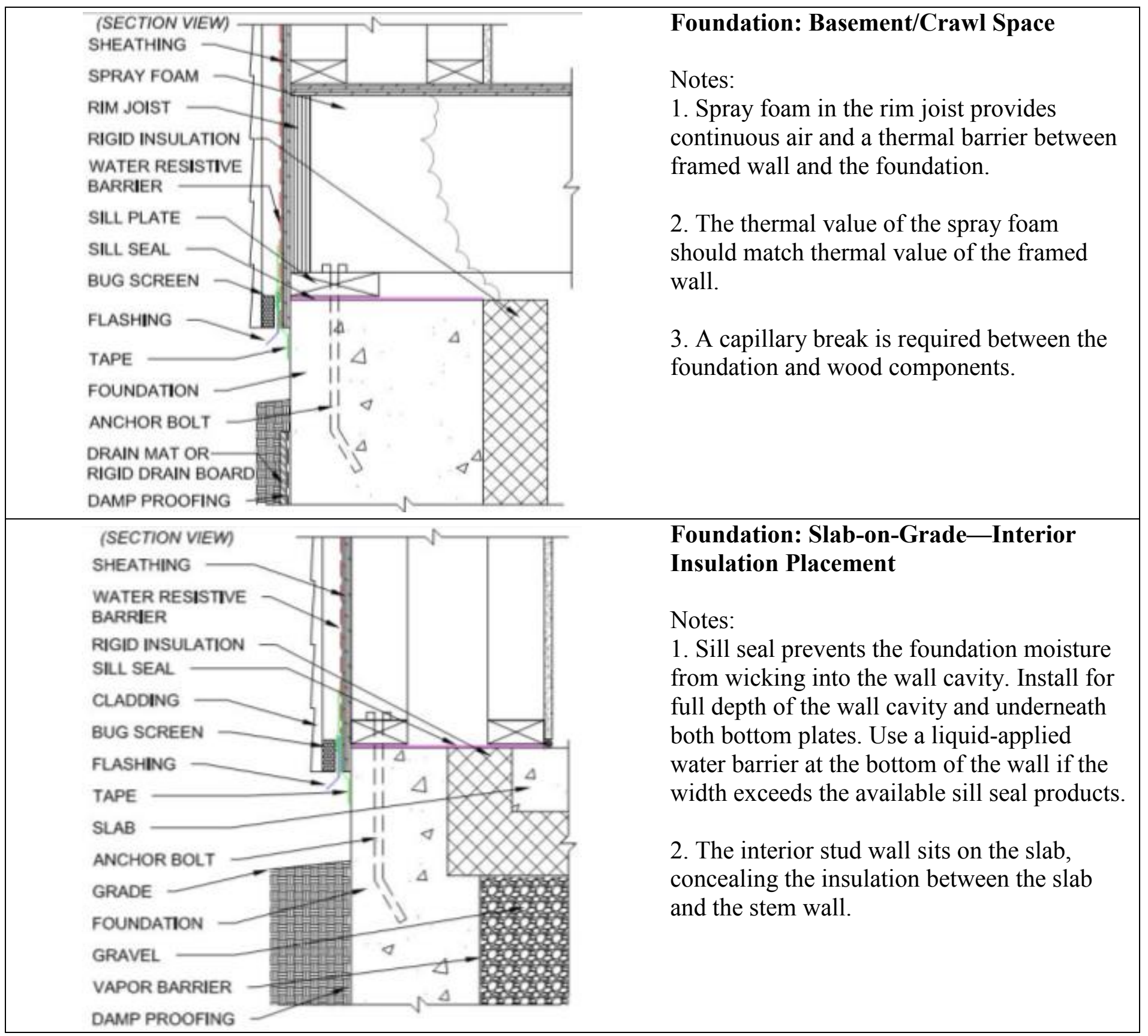




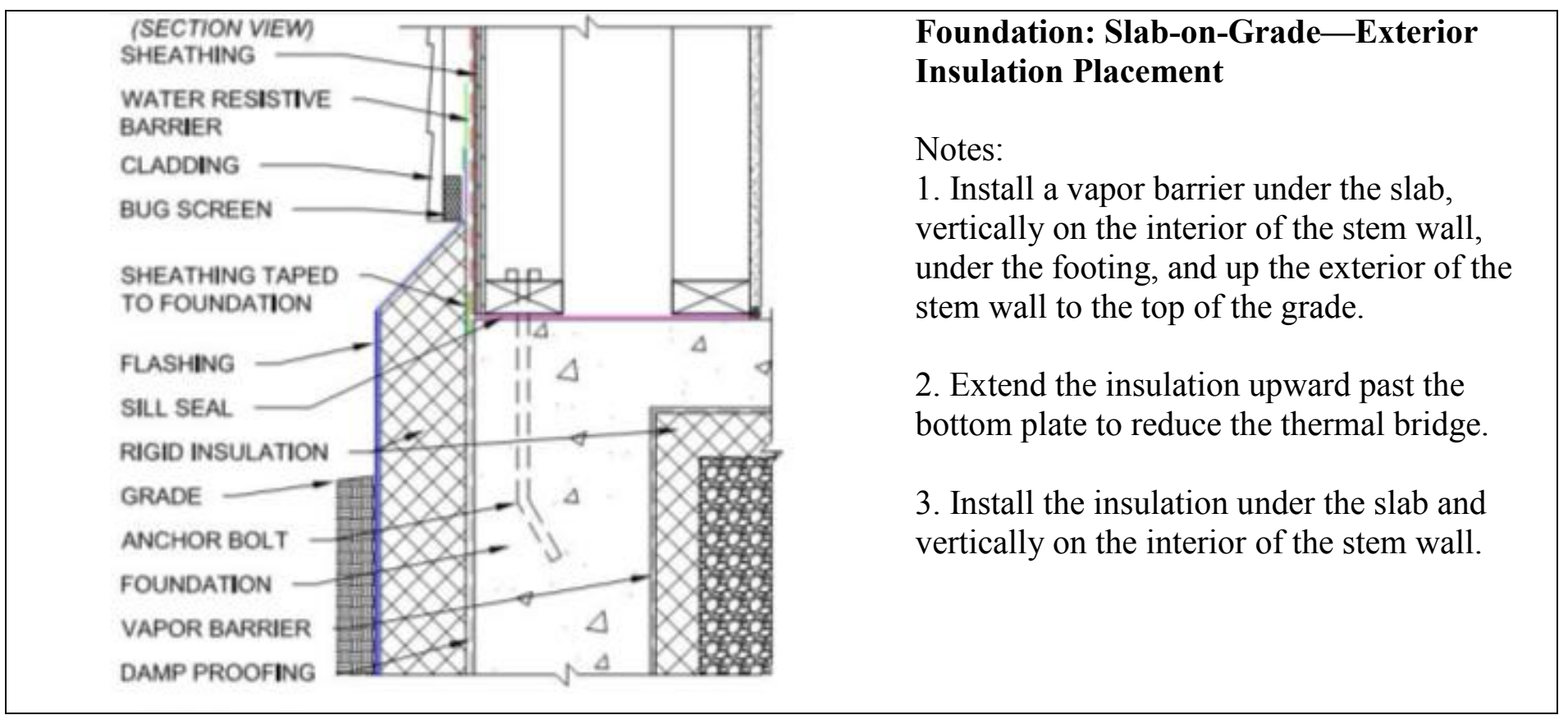




\subsection{Wall Framing}

After the proper moisture-control strategies have been installed at the foundation level, wall framing can begin. The exterior load-bearing wall will be constructed first. The builder has the flexibility to decide if the second wall is installed next or if it is installed after the building is dried in. The following details are independent of that sequencing.

\section{(PLAN VIEW)}

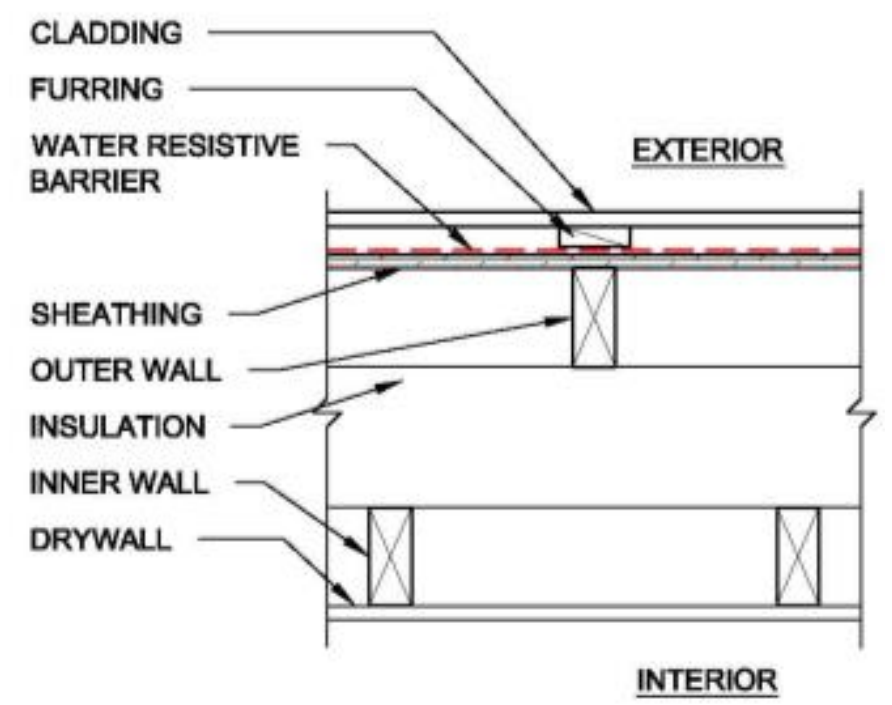

\section{Typical Wall}

\section{Notes:}

1. The inner and outer wall framing are typically framed with $2 \times 4 s$ at 16 in. on center. The inner and outer wall studs do not need to be offset.

2. The distance between the inner and outer wall framing varies depending on the desired R-value. Overall depth typically does not exceed 16 in. (Refer to the insulation manufacturer's installation guidelines.)

3. Air/water barrier options

a. Rolled sheet, mechanically fastened

b. Rolled sheet, self-adhering

c. Liquid-applied

d. Impregnated sheathing

4. Vented cladding options

a. Wood, cement board, etc., on furring (shown)

b. Vinyl siding 
(PLAN VIEW)

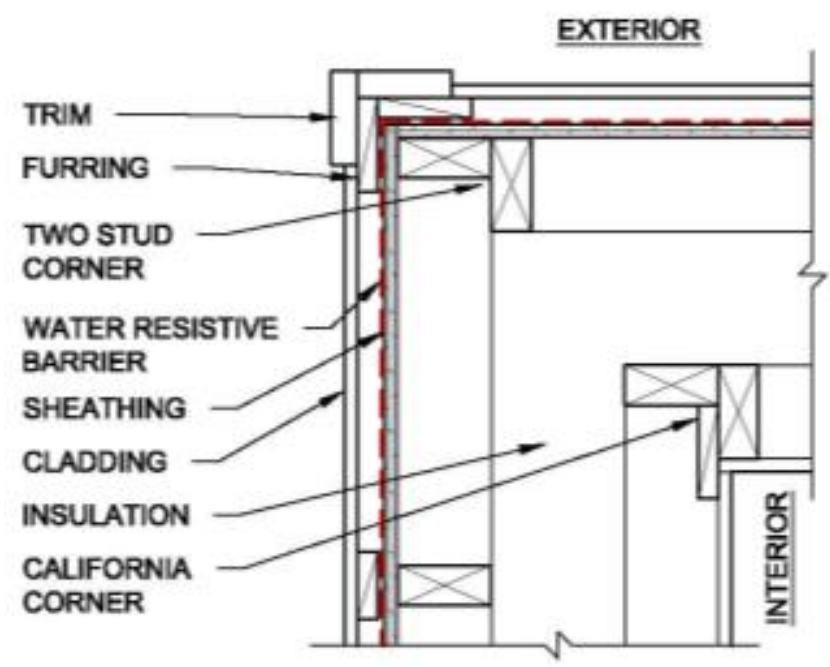

\section{Exterior Corner}

Notes:

1. Avoid unnecessary framing at the exterior corners.

2. California corner drywall support options:

a. 1 x 4 nailer (shown)

b. Drywall clips

\subsection{Roof Connection}

Either a vented attic or a cathedral ceiling can be constructed in conjunction with double-wall construction. Continuity of the air barrier must be achieved with either construction method; however, high R-value vented roof assemblies are simpler from a moisture-management perspective.

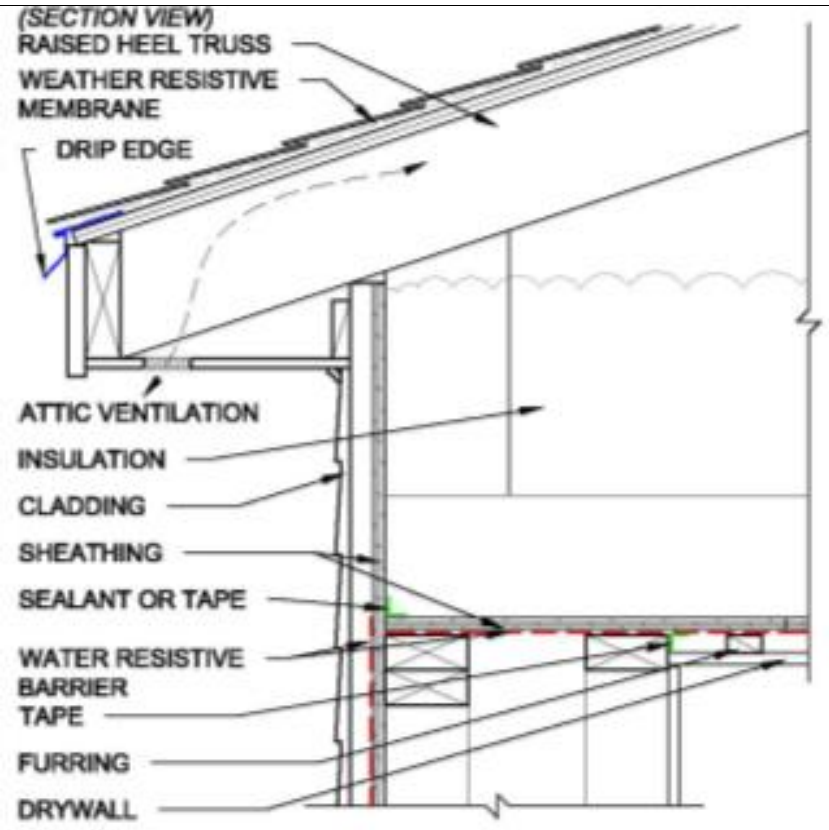

\section{Roof/Wall Connection: Unconditioned Attic}

Notes:

1. A raised heel truss allows for full-depth ceiling insulation at the outer edge of the wall.

2. Sheathing is installed over the top plates to provide blocking for blown-in insulation and to connect the exterior airtight layer on the wall to the airtight layer under the ceiling.

3. A sheathing sealant at top of the inner and outer wall framing connects the airtight layers. Air barrier tapes are recommended instead of caulk. 


\subsection{Rim/Band Joist Details}

No special framing techniques are required to accommodate double walls at the rim/band joist; however, additional blocking will be required if cellulose or fiberglass insulation will be blown into the rim.

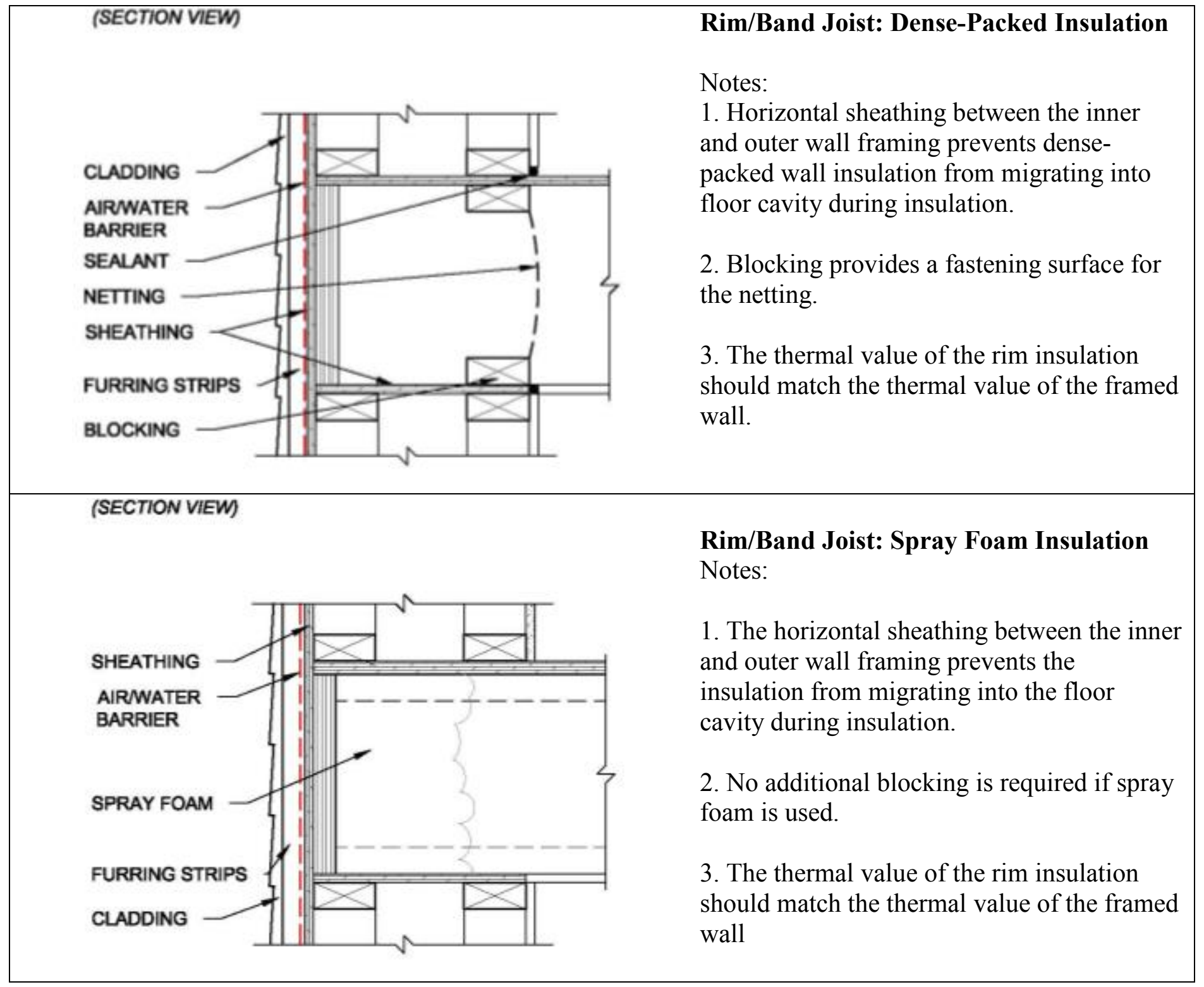

\subsection{Windows and Doors}

Windows can be installed flush with the exterior structural sheathing to make incorporating them into the drainage plane simple. They can also be installed in the center of the wall to improve the thermal performance of the frame. Thermal modeling has shown little advantage to moving them all the way to the interior compared to locating them in the center. ${ }^{1}$ Doors must be installed at

\footnotetext{
${ }^{1}$ See http://www.passivhausplaner.eu/MusterPH_Projektdoku_Bild/passivhaus_Butcher_Butcher_DenbyDale.pdf.
} 
the interior edge of the framing to allow for full operation unless detailed to allow for a swing greater than $90^{\circ}$. In either case, moisture-management details must be clearly identified on the plans and executed as such during installation to reduce the potential for bulk water leaks.

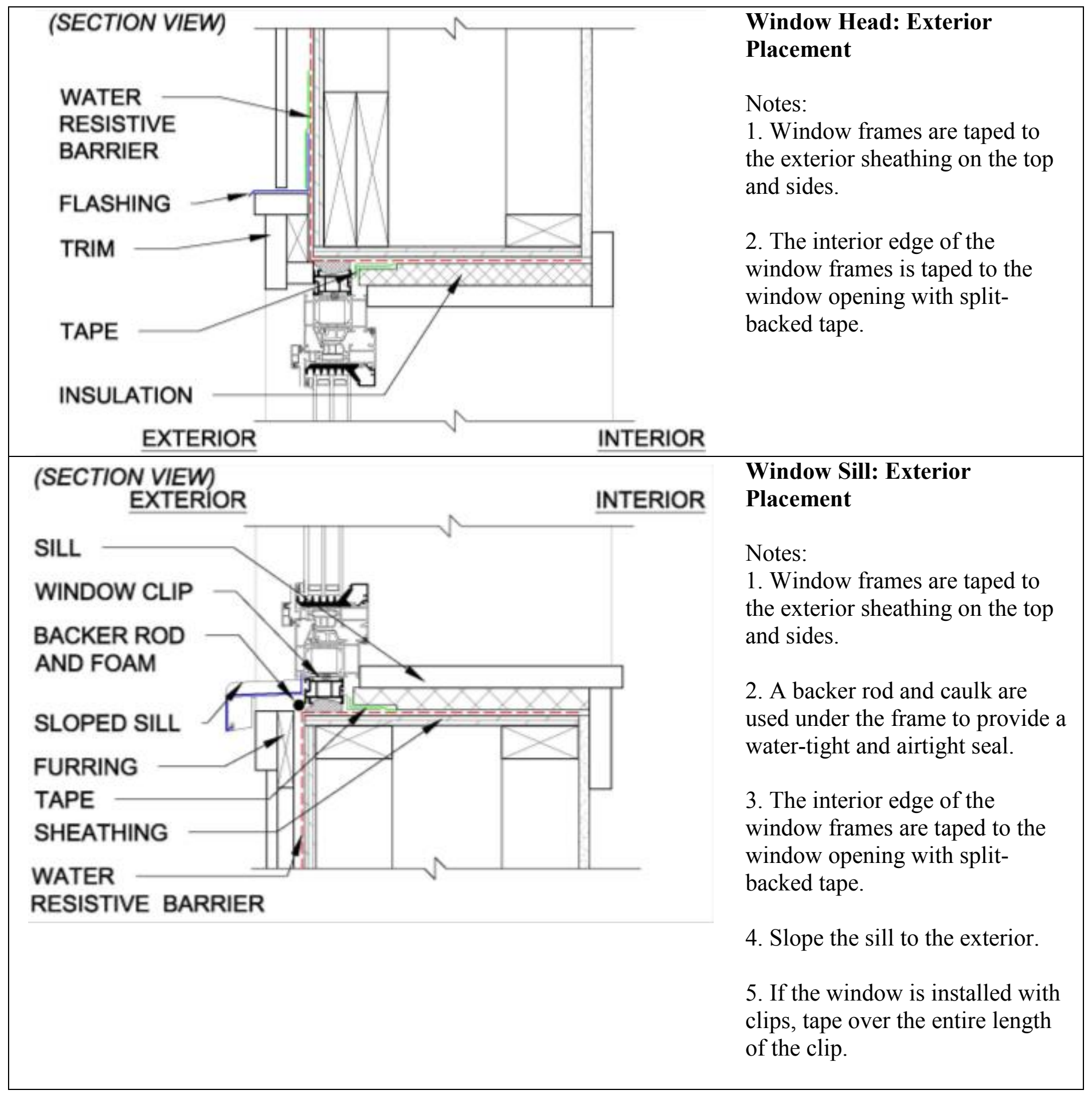




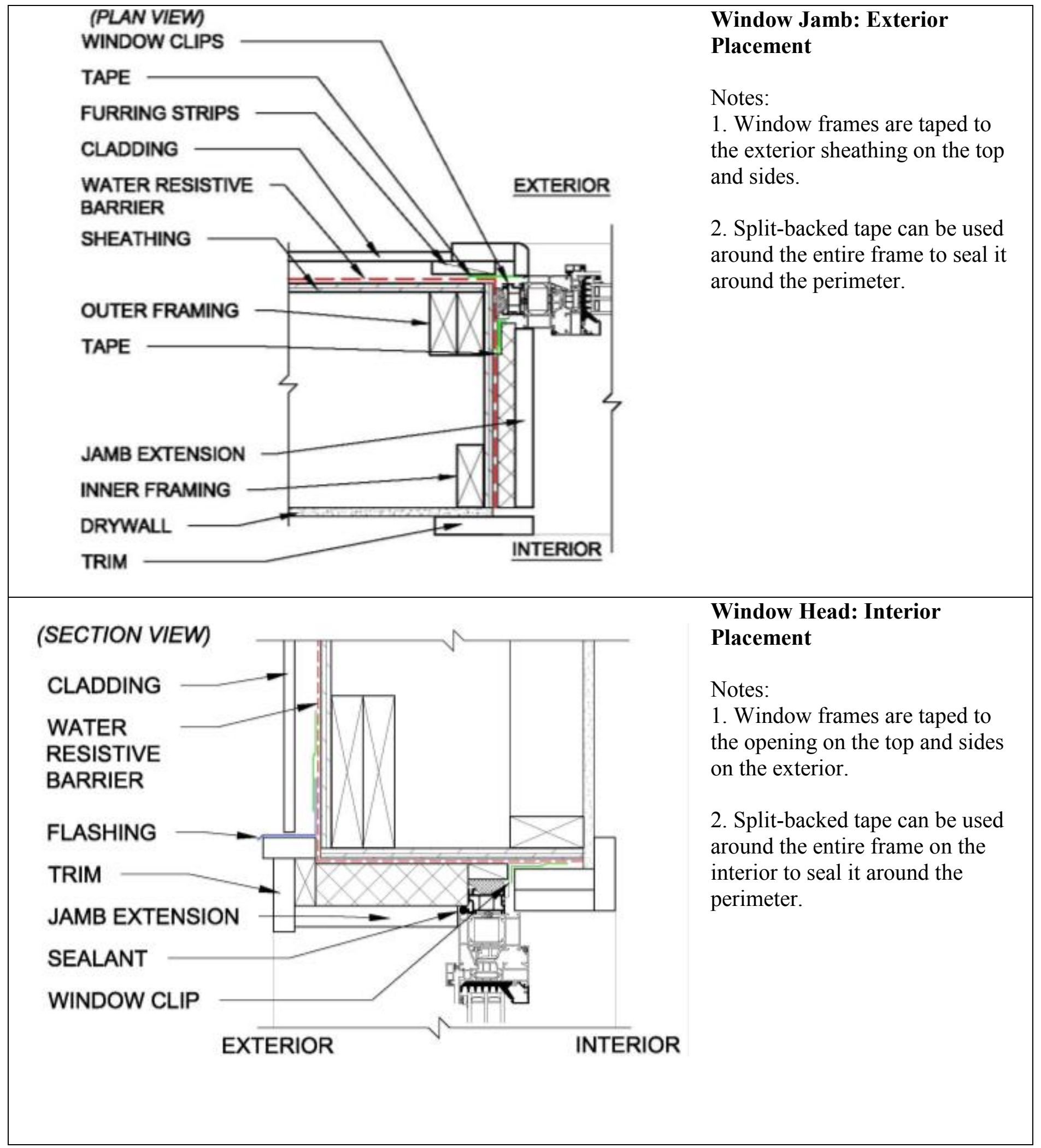




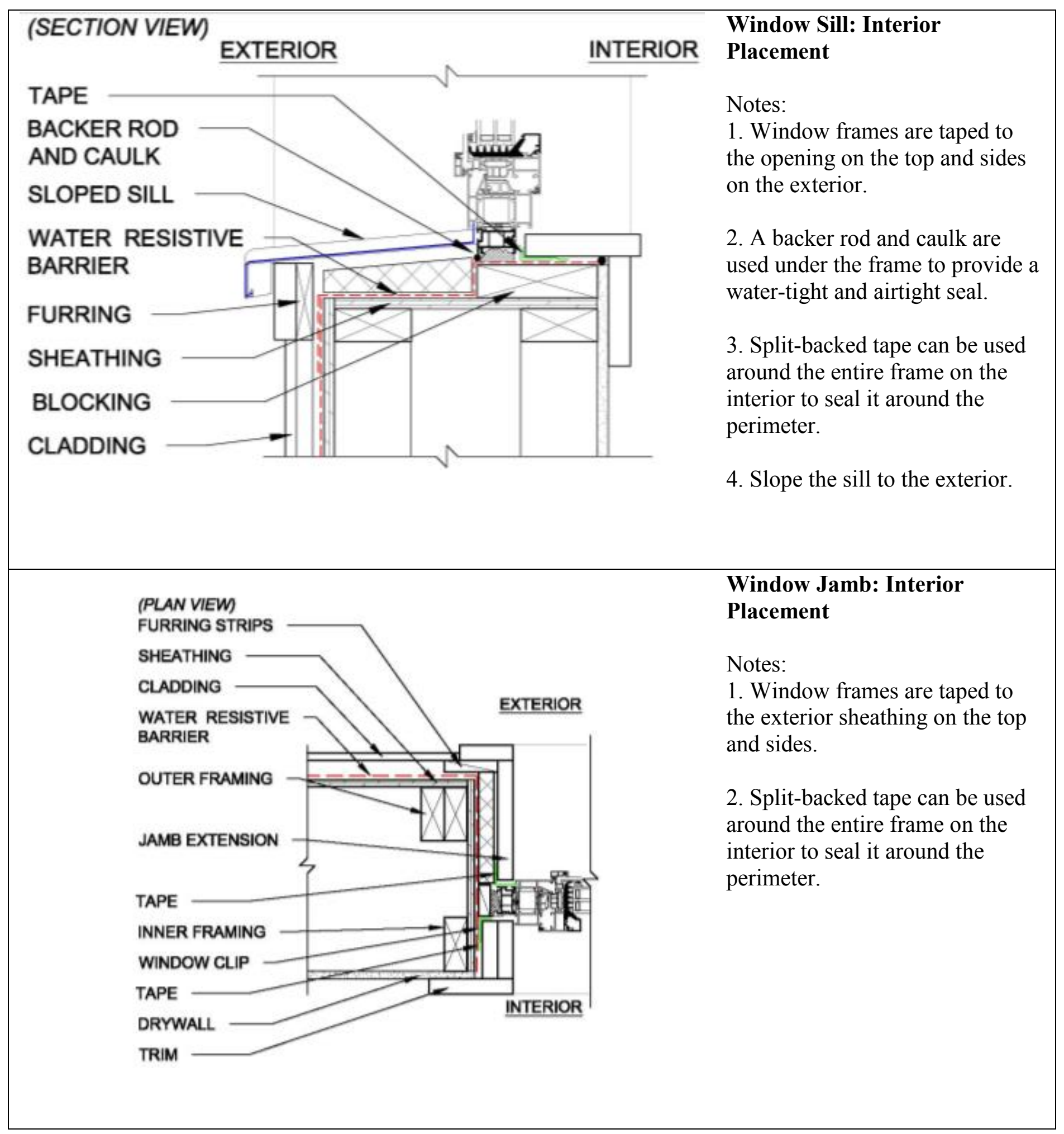




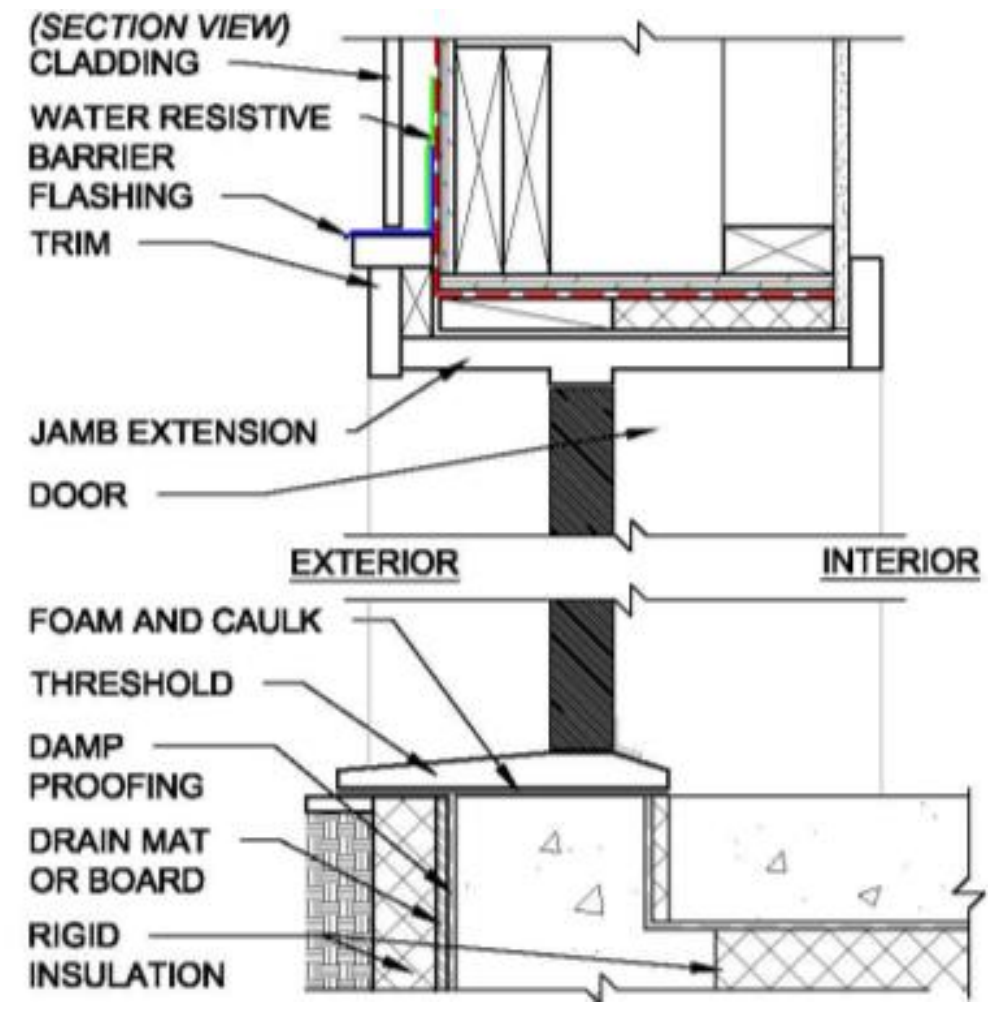

(PLAN VIEW)

FURRING STRIPS

SHEATHING

CLADDING

WATER RESISTIVE BARRIER

OUTER FRAMING

DOOR

INSULATION

SEALANT

INNER FRAMING

DRYWALL

TRIM

\section{Door Head and Sill}

Notes:

1. The door sill is difficult to seal. Use a backer rod and caulk when possible.

2. Tape the door jambs to the opening on the interior and exterior.

\section{Door Jamb}

Notes:

1. Special detailing is needed if the door is not mounted flush with the interior framing. 


\subsection{Weather-Resistive Barrier}

As noted above, the WRB can be a building wrap, liquid applied, or impregnated onto the structural sheathing at the factory. Depending on which method is being used, various steps in the following sequence can be eliminated. These have been indicated in the notes.

\begin{tabular}{|l|l|}
\hline SEWRAP & $\begin{array}{l}\text { Note: If using liquid-applied or impregnated } \\
\text { WRB, skip to Step 3. }\end{array}$ \\
Step 1. (House wrap only) Install house wrap. \\
a. Tape all seams with manufacturer- \\
recommended tape. \\
b. Cut at the window opening, as shown.
\end{tabular}




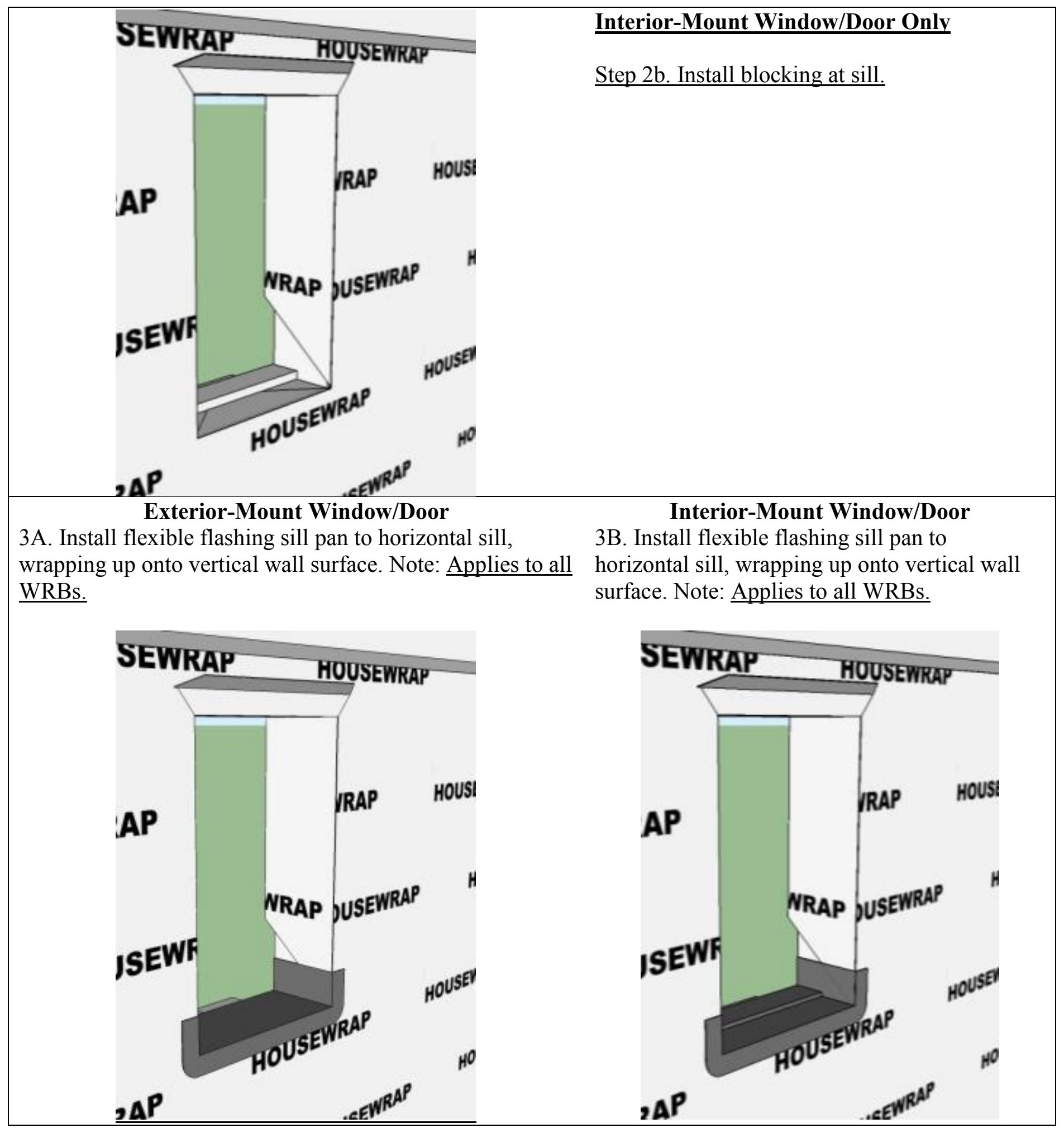




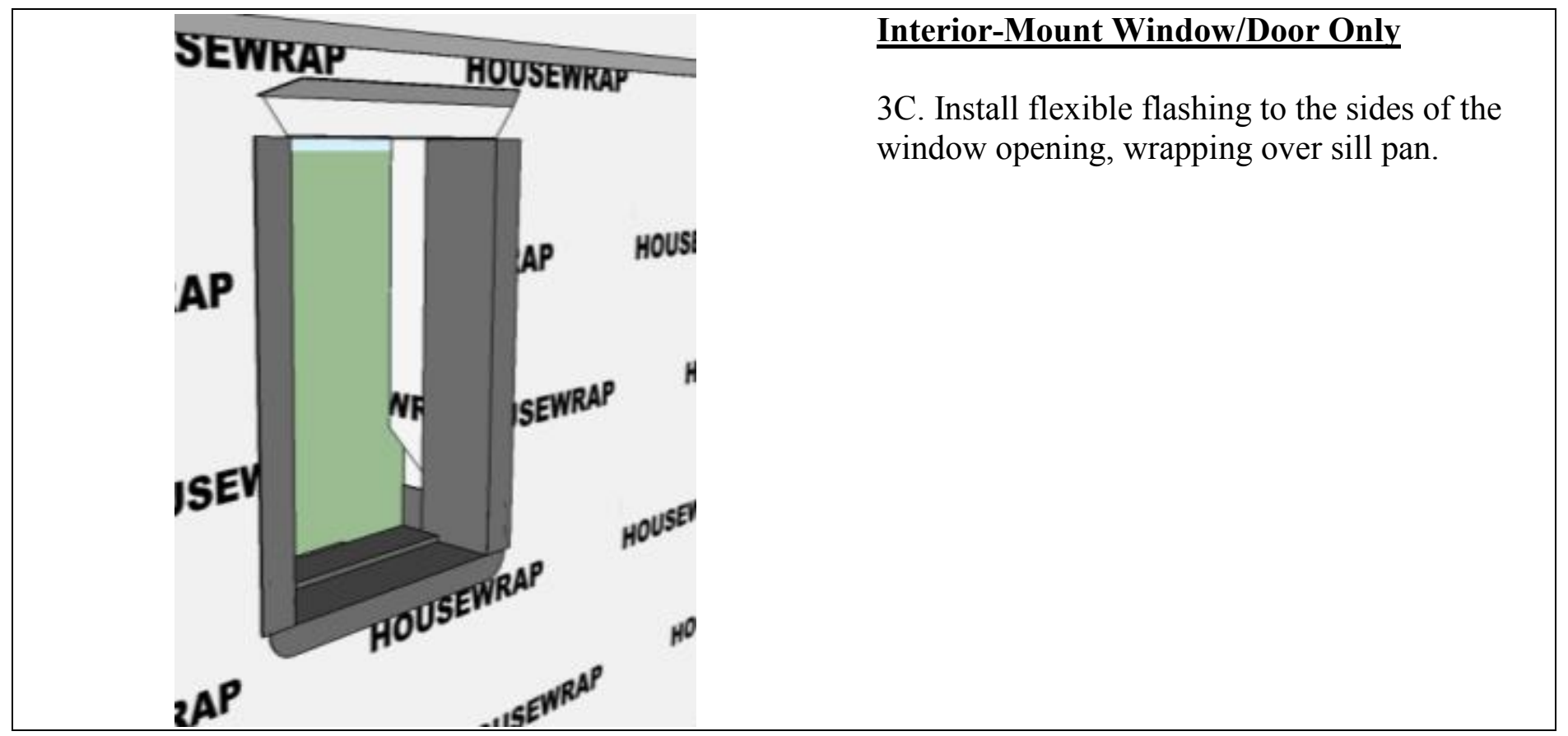

\section{Exterior-Mount Window/Door}

4A. Install window.

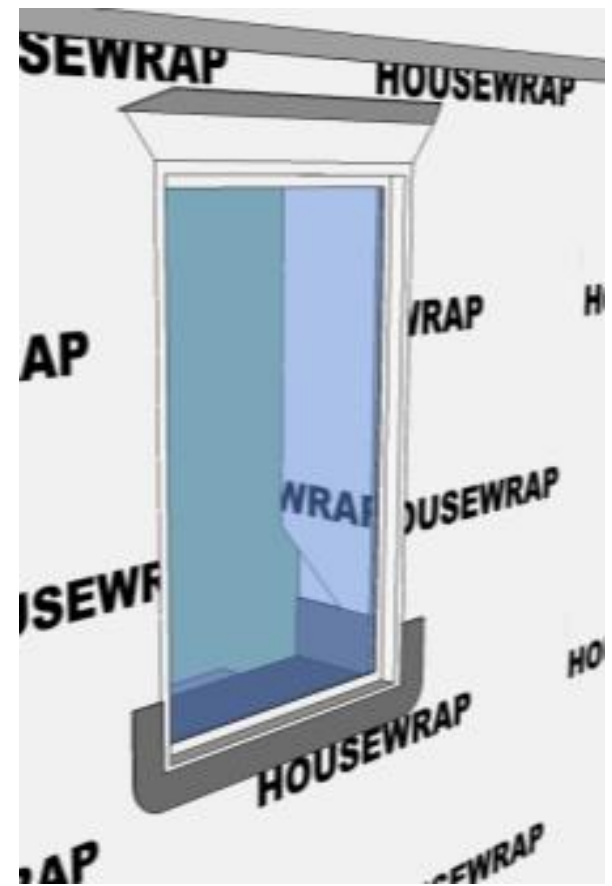

Interior-Mount Window/Door

4B. Install window.

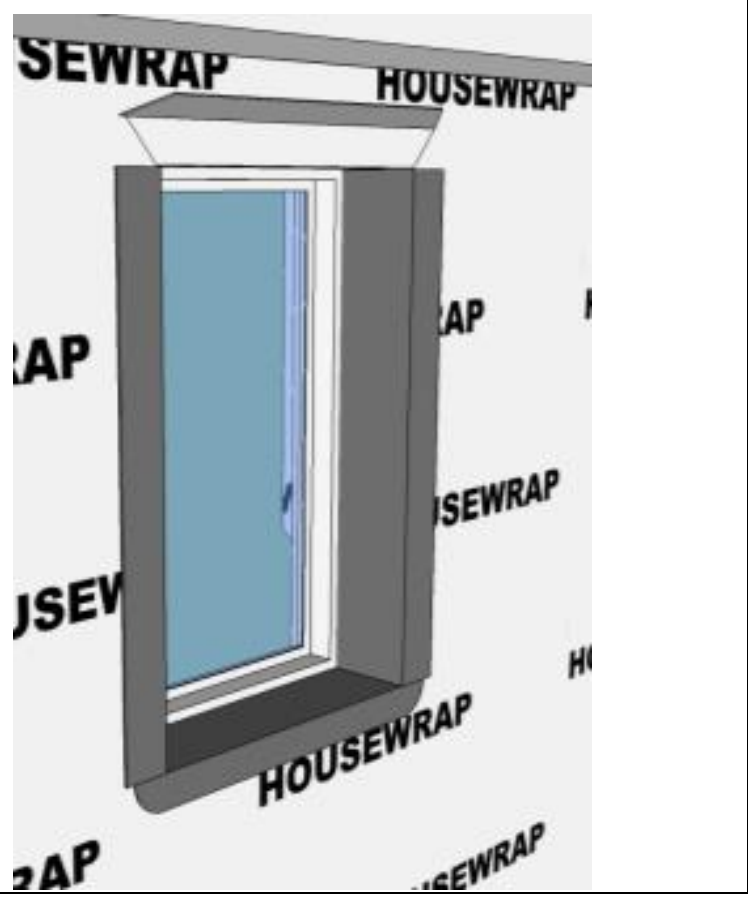


5A. Install 4-in. flashing tape at jambs spanning from the window frame to the WRB. ${ }^{\mathrm{a}}$

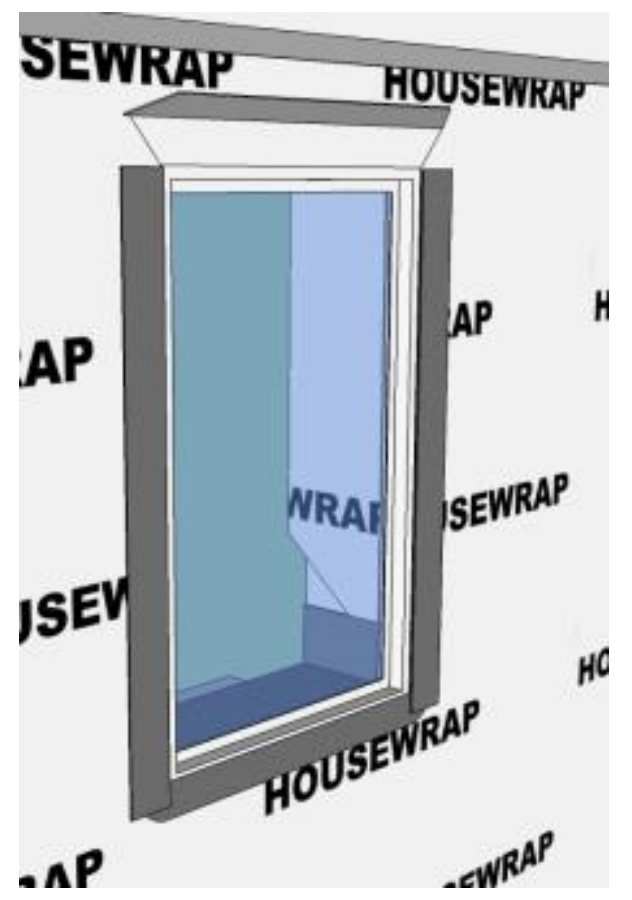

a Alternatively, split-back flashing tapes may be attached to the window before installation. Once installed, the second backing is removed from the tape and attached to the WRB.
5B. Tape window jambs to WRB. ${ }^{\mathrm{b}}$

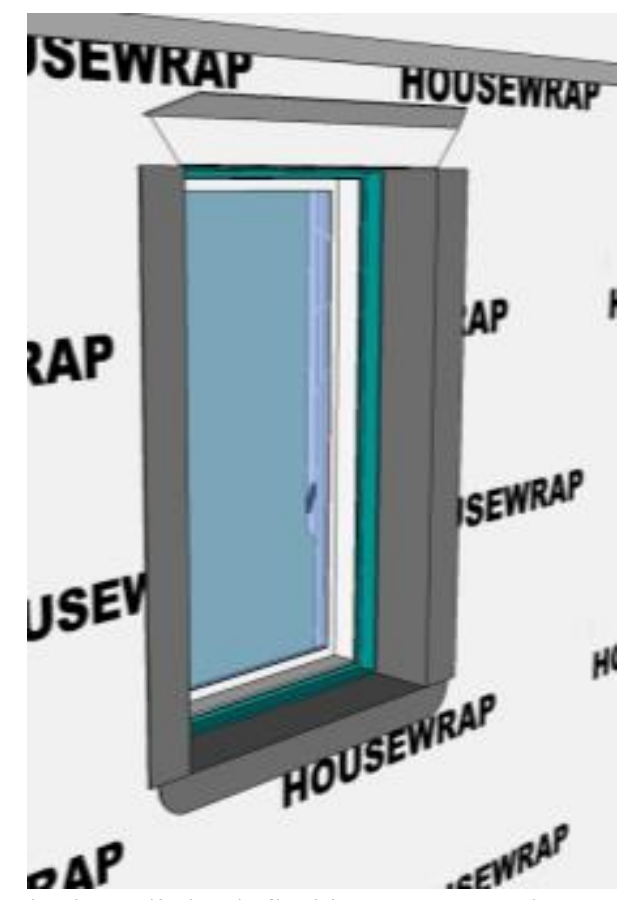

b Alternatively, split-back flashing tapes may be attached to the window before installation. Once installed, the second backing is removed from the tape and attached to the WRB. 
6A. Install 4-in. flashing tape at the head spanning from the window frame to the moisture barrier.

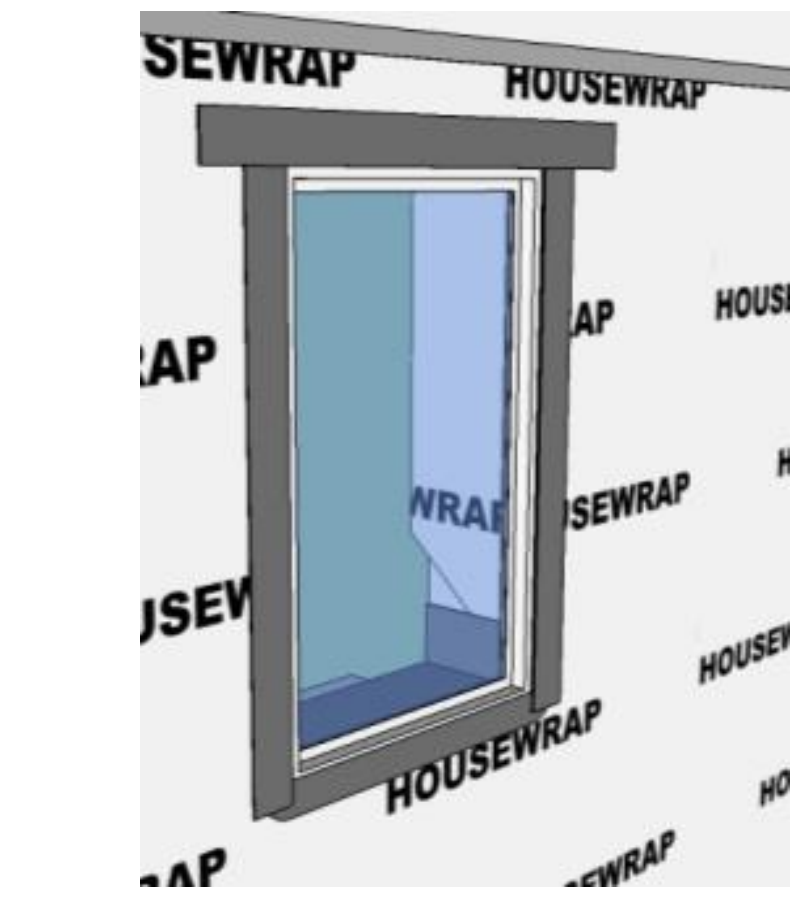

6B. Install 4-in. flashing tape at the head spanning from the window frame to the moisture barrier.

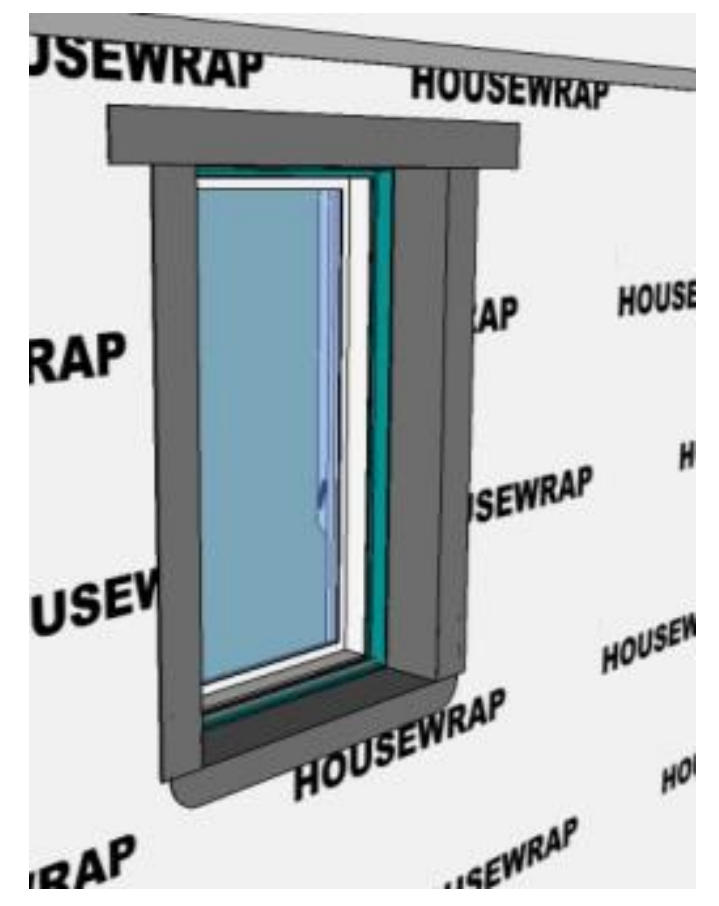

\subsection{Insulation}

Before the insulation is installed, ensure that the exterior wall penetrations have been boxed out to prevent disruption to the insulation should repairs or access be needed in the future. All exterior wall penetrations should be air sealed at this time regardless of whether the airtight layer is on the exterior or interior of the wall.

If the airtight layer will be on the exterior, all seams and penetrations should be taped and sealed before the insulation is installed. All connections to the foundation, roof, and wall corners should also be airtight at this time. An air-leakage test before the insulation is installed is highly recommended to ensure that the airtight layer is meeting the project goals. Repairs, if necessary, will be easiest before the insulation is installed.

After the air sealing is complete, the insulation can be installed. A single type or a combination of types can be used. Refer to the insulation ratios discussed in Section 3: Technical Description to determine the proper levels of air-impermeable and air-permeable insulation if a hybrid strategy is desired. 


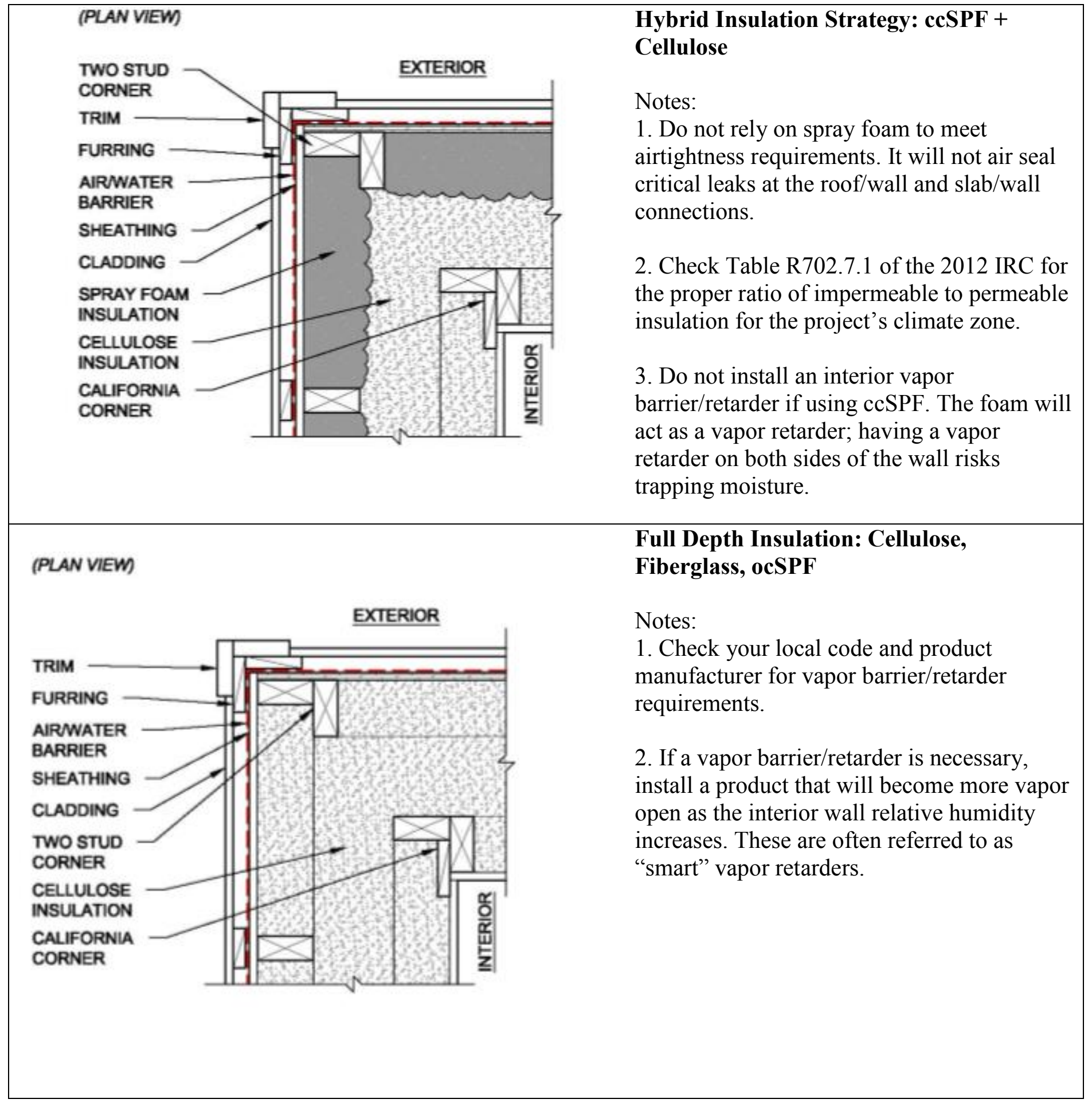

\subsection{Drywall}

If an interior airtight layer is being installed instead of one on the exterior, it must be installed before the drywall. Because of the number of electrical penetrations on an interior wall, it is not recommended that the electrical outlets or switch plates be installed on the interior stud wall of 
the double-wall assembly. Instead, sheathing should be installed on the interior side of the interior wall and taped and sealed at any necessary plumbing and electrical penetrations. A separate chase wall should then be constructed on the interior of the double wall and all electrical boxes installed in that space. Airtightness testing should be conducted after the interior sheathing has been sealed and incorporated into the ceiling and foundation airtight layers. After the project goals have been achieved, the drywall can be installed.

\subsection{Cladding Attachment}

Ventilated cladding is required by code if a Class I or Class II vapor retarder is not installed on the interior of the wall in Climate Zones 5 and higher. It is recommended that vapor retarders not be installed on high R-value walls so that the walls can dry to both the interior and the exterior. For this reason, vented claddings are highly recommended when high R-value wall assemblies are constructed in cold climates. If needed, a smart vapor retarder that becomes more open as the humidity increases is recommended. However, a vented cladding is still recommended.

\section{Exterior Mount}

1. Install flashing at head.

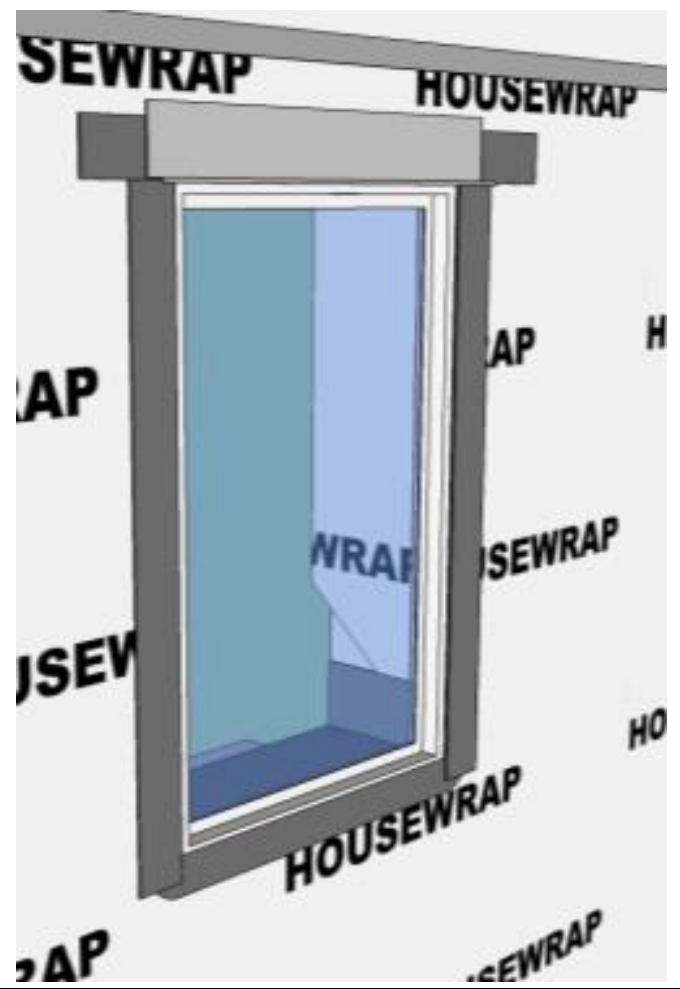

\section{Interior Mount}

1. Install flashing at head.

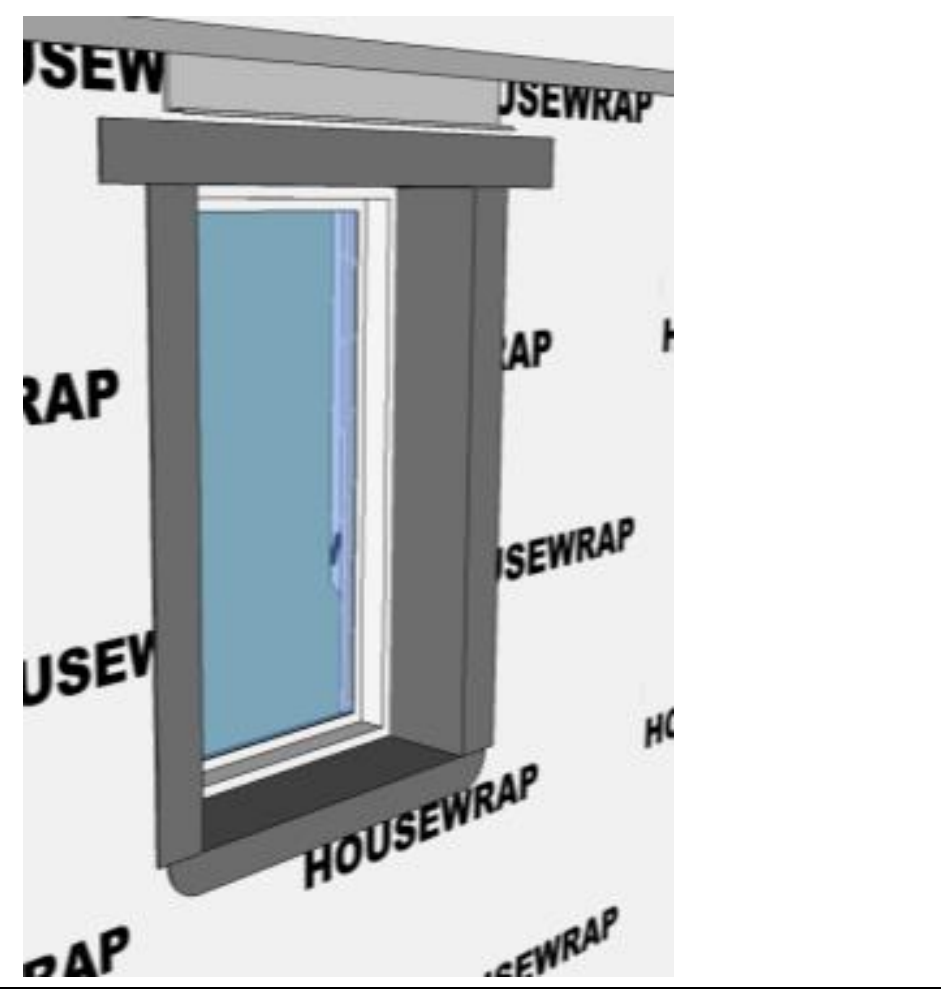




\section{Exterior Mount}

2. Install furring strips.

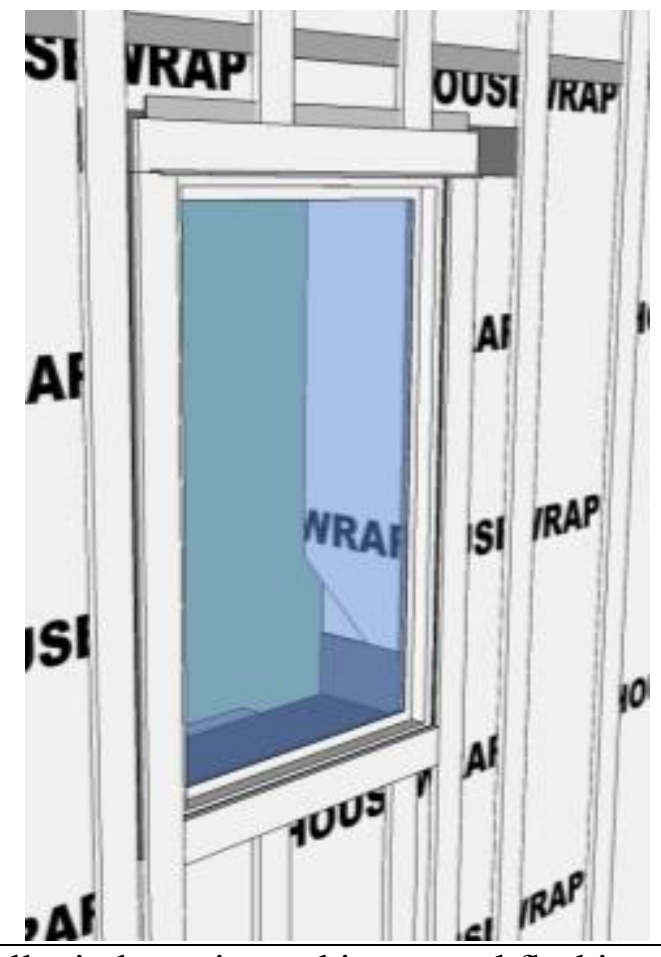

\section{Interior Mount}

2. Install furring strips.

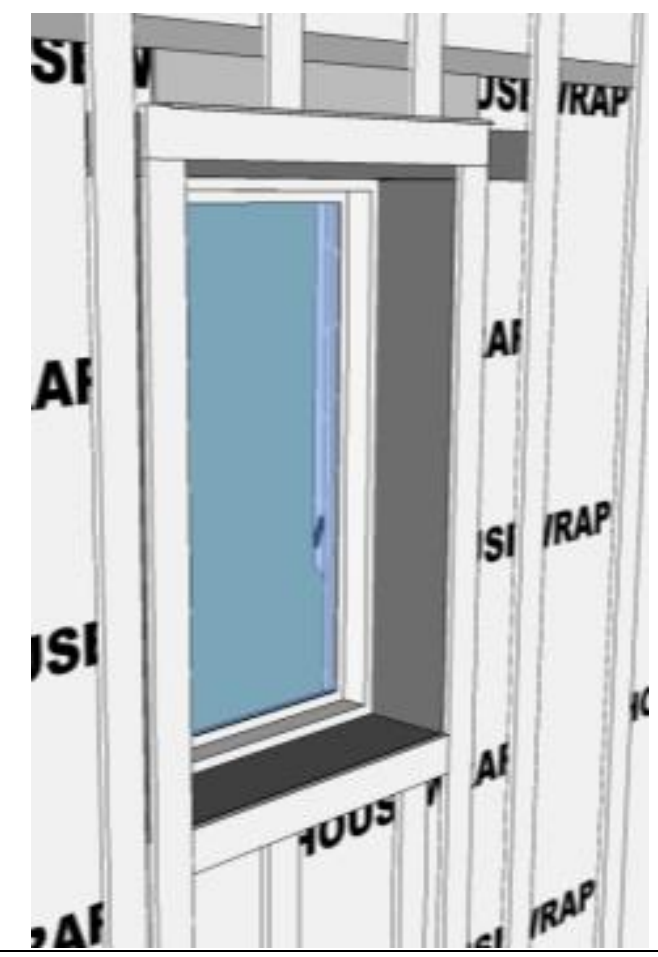

3. Install window trim and integrated flashing at sill. 3. Install window trim and integrated flashing at sill.
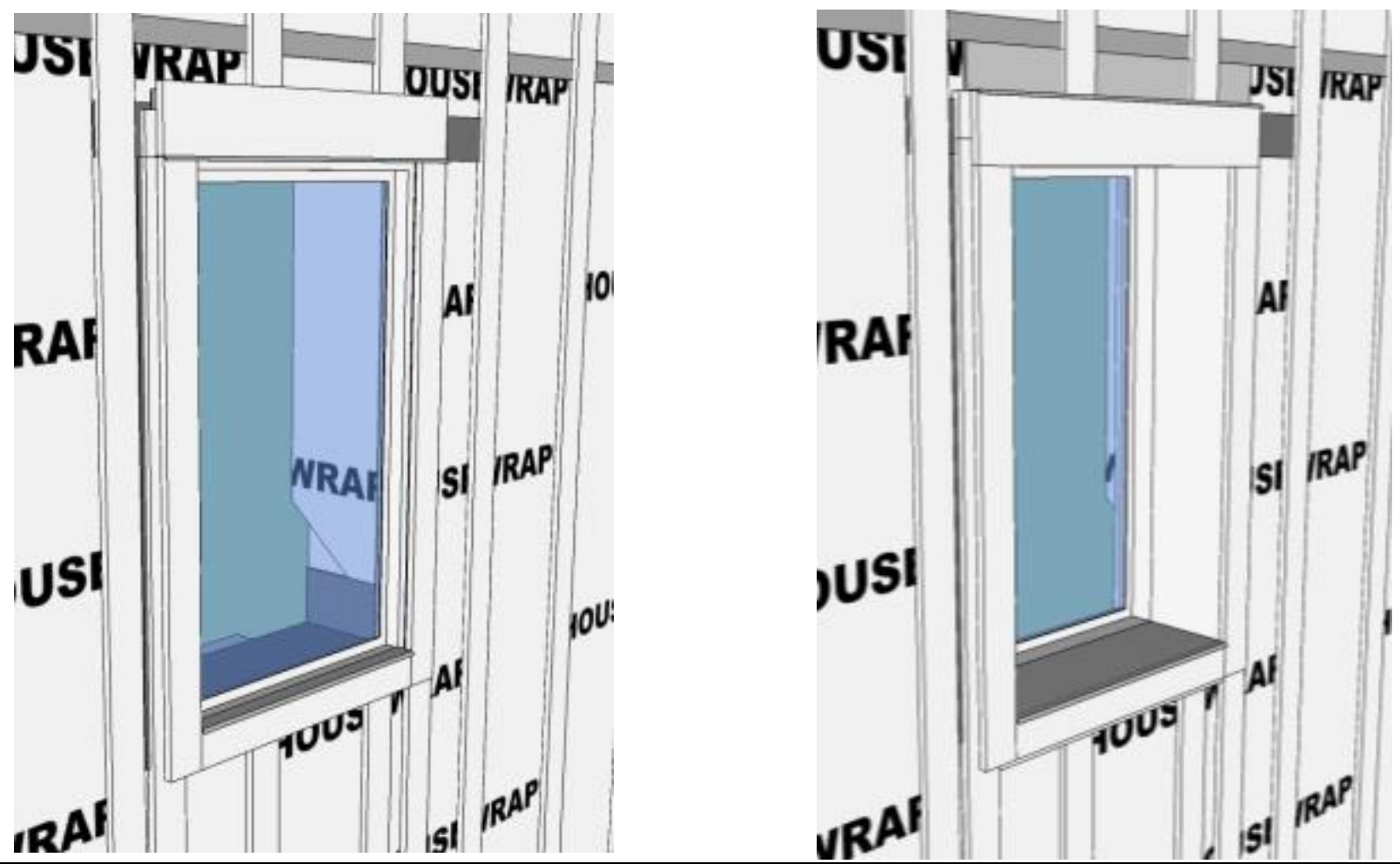


\section{Exterior Mount}

4. Install cladding.

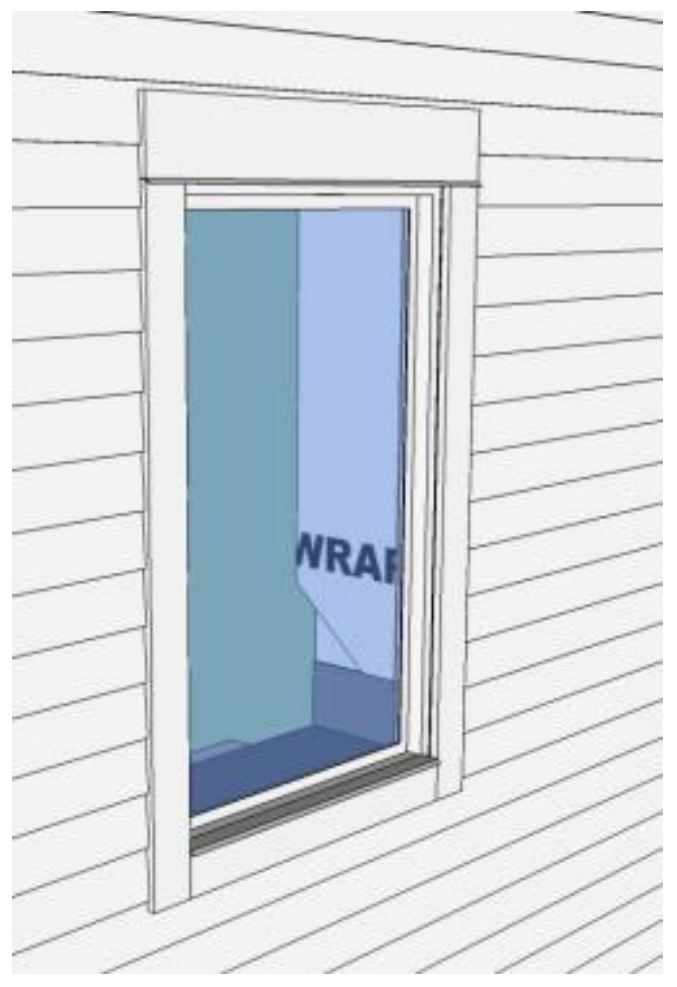

\section{Interior Mount}

4. Install cladding.

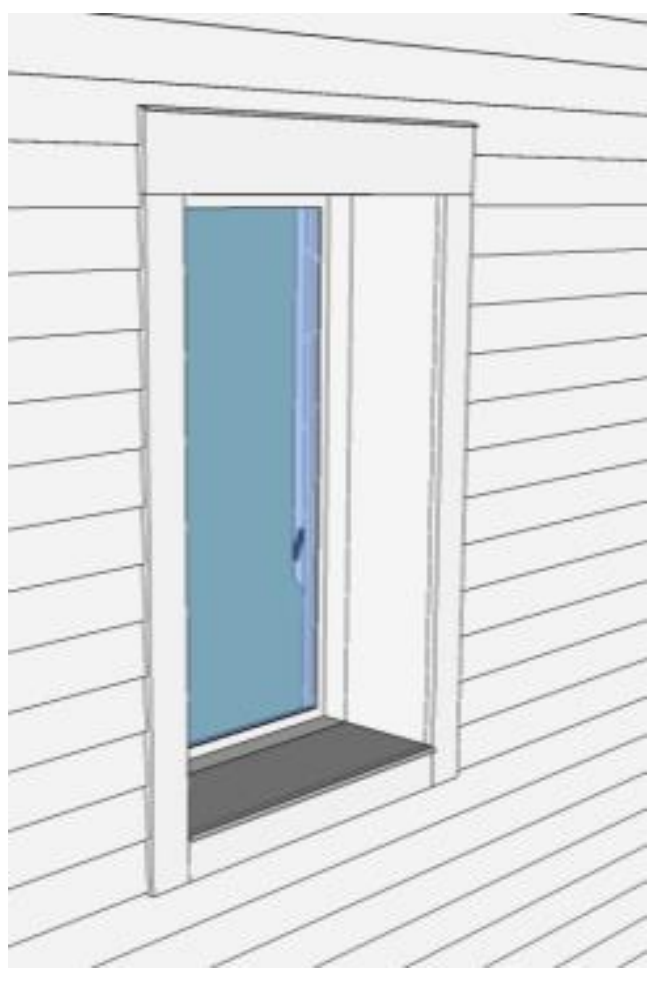




\section{Verification Procedures and Tests}

In addition to visual inspections to verify air-sealing measures and proper installation of the insulation, two tests should be conducted on every high-performance home. The first is a blower door test to verify that the airtight layer meets the projects goals. The second is testing the ventilation system to ensure that flow rates are as specified and that the system is balanced.

\subsection{Air-Leakage Testing}

Air-leakage testing is a good idea on any construction project, but it is essential on a home that has high R-value walls to ensure that the wall assembly is airtight. The goal is to prevent warm interior air from entering the wall cavity during the cold periods of the year. This warm air can condense on colder exterior surfaces inside the wall cavity, and over time it can cause moisturerelated problems such as mold growth and decay.

Blower door testing is used regularly on energy-efficient projects throughout the United States. Trained professionals are located in every state. Section N11024 of the 2012 IRC requires that all new construction be blower door tested, and many states and municipalities have begun mandating this testing.

The basic equipment consists of a door frame, a sheet to cover the frame, a fan to pressurize or depressurize the home, and gauges to measure the flow through the fan. Typically depressurization tests are run because it is easier to detect the location of the leaks from inside the home. It is recommended that homes with high R-value walls be tested before the insulation is installed and then again before the drywall is installed. Waiting until construction is complete could result in the inability to fix problematic air leaks.

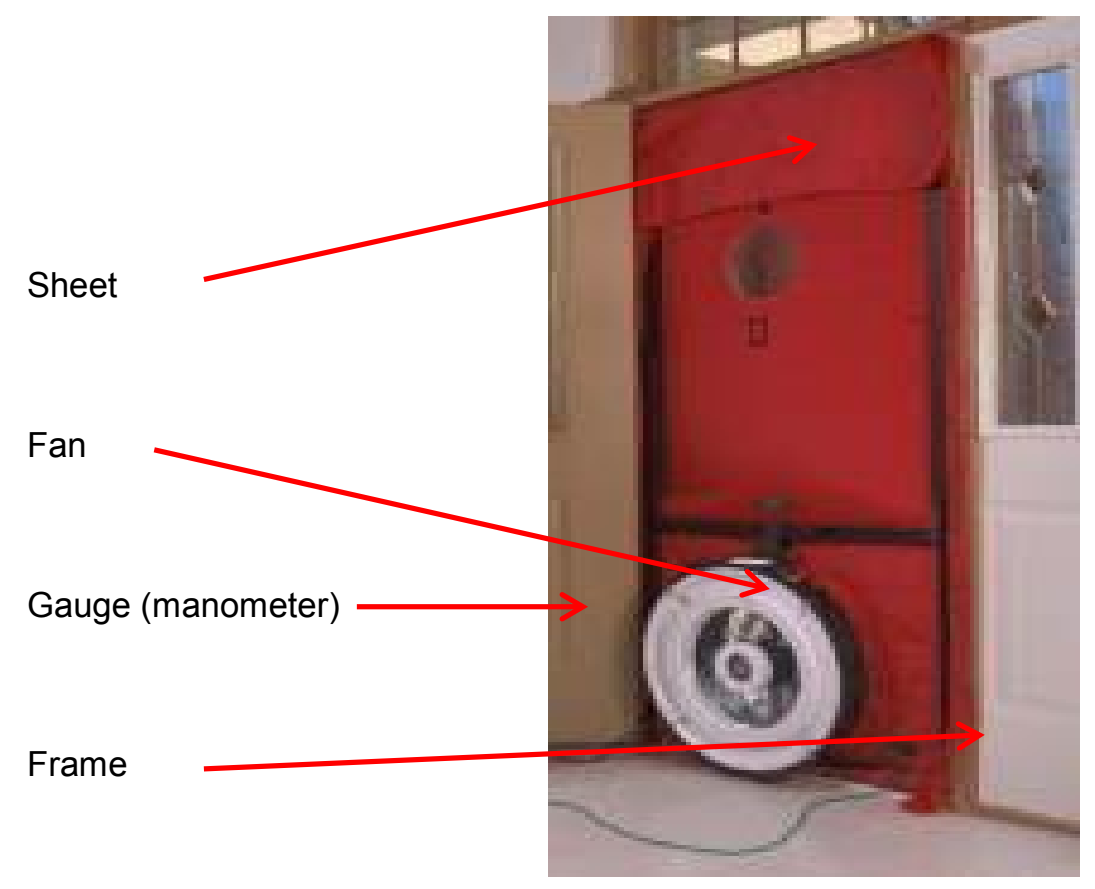

Figure 22. Typical blower door equipment used to detect air leakage through the building envelope 


\subsection{Ventilation System Balancing and Commissioning}

In addition to blower door testing, it is highly recommended that the mechanical ventilation system be tested and balanced. Although exhaust-only ventilation has been shown to work, it is highly recommended that super-insulated, airtight homes incorporate continuously balanced mechanical ventilation. Stale, moist indoor air must be removed and replaced with fresh outdoor air. A balanced heatrecovery ventilation system performs both these tasks and significantly reduces the amount of energy lost from the outgoing airstream. However, if these systems are not balanced_-incoming air and outgoing air flows are within $10 \%$ of each other-moisture removal and heat exchange can be compromised, and interior humidity could reach undesirable levels.

To prevent this, the incoming and outgoing airstreams at the ventilation unit should be measured and adjusted if they are more than the $10 \%$ different. Low-flow balometers or power-capture hoods can be used to measure the flow rates. The air flow at each of the supply and return registers should also be measured to verify that the amount of air being exhausted and supplied to the various rooms is as designed. 


\section{References}

Aldrich, R., Arena, L., and Zoeller,W. 2010. Practical Residential Wall Systems: R-30 and Beyond. Best Conference Proceedings, 2010, Clearwater, FL.

Arena, L. 2014. The Hygrothermal Performance of an R-40 Cellulose Wall in Climate Zone 5 A. (Building America Technical Report.) Washington, DC: U.S. Department of Energy.

Carpenter S.C., and Schumacher C. 2003. Characterization of Framing Factors for WoodFramed Low-Rise Residential Buildings. ASHRAE Transactions. Vol. 109, Pt. 1 (February), pp. 101-108.

Perkins, Anne. Director of Homeownership Programs, Rural Development, Inc. Personal conversation. October 2009.

Straube, J., and J. Smegal. 2009. Building America Special Research Project: High-R Walls Case Study Analysis. (Technical Report RR-0903.) Somerville, MA: Building Science Corporation.

Tauer, Jonathan. President, Celluspray Insulation. Personal conversation. October 2009.

Ueno, K and Straube, J . 2008. Laboratory Calibration and Field Results of Wood Resistance Humidity Sensors. BEST 1 Conference. 


\section{Appendix A: Compliance with U.S. Department of Energy Zero Energy Ready Home Criteria}

\begin{tabular}{l|c}
\hline Area of Improvement & Mandatory Requirements \\
\hline Envelope & $\checkmark$ Ceiling, wall, floor, and slab insulation shall meet or exceed \\
& 2012 IECC levels \\
\hline
\end{tabular}

ENERGY STAR ${ }^{\circledR}$ Version 3 (Rev. 07) compliance

Water Management System Builder Checklist

1. Water-Managed Site and Foundation

1.3 Capillary break beneath all slabs (e.g., slab on grade, basement slab) except

crawlspace slabs using either: $\geq 6$ mil polyethylene sheeting, lapped 6-12 in., or $\geq 1$ in. extruded polystyrene insulation with taped joints.

1.5 Continuous drainage plane behind exterior cladding, properly flashed to foundation (WMS 2.2)

1.6 Window and door openings fully flashed (WMS 2.3)

1.13 Materials with signs of water damage or mold (WMS 4.5)

Thermal Enclosure System Rater Checklist

2. Quality-Installed Insulation

2.1 Ceiling, wall, floor, and slab insulation levels shall:

2.1.1 Meet or exceed 2009 IECC levels

2.2 All ceiling, wall, floor, and slab insulation shall achieve RESNET-defined Grade I installation or, alternatively, Grade II for surfaces that contain a layer of continuous, airimpermeable insulation $\geq$ R-5 in Climate Zones 5 to 8

3. Fully- Aligned Air Barriers

3.1 Walls

3.1.1 Walls behind showers and tubs

3.1.3 Attic knee walls

4. Reduced Thermal Bridging

4.1 For insulated ceilings with attic space above (i.e., non-cathedralized), Grade 1

insulation extends to the inside face of the exterior wall below at these levels: CZ 1-5: $\geq$

R-21; CZ 1-5: $\geq$ R-21

4.4 Reduced Thermal Bridging at above-grade walls

4.4.4 Double-wall framing

4.4.5 Advanced framing

4.4.5a All corners insulated $\geq \mathrm{R}-6$ to edge

4.4.5b All headers above windows $\&$ doors insulated $>=\mathrm{R}-3$ for $2 \times 4$

framing or equivalent cavity width

4.4.5c Framing limited at all windows and doors to one pair of king studs, plus one pair of jack studs per window opening to support the header and sill 


\section{Air Sealing}

4.4.5d All interior/exterior wall intersections insulated to the same R-value as the rest of the exterior wall

5.1 Penetrations to unconditioned space fully sealed with solid blocking or flashing as needed and gaps sealed with caulk or foam

5.1.1 Duct/flue shaft

5.1.2 Plumbing/piping

5.1.3 Electrical wiring

5.2 Cracks in building envelope fully sealed

5.2.1 All sill plates adjacent to conditioned space sealed to foundation or subfloor with caulk, foam, or equivalent material. Foam gasket also placed beneath sill plate if resting atop concrete or masonry and adjacent to conditioned space 5.2.3 Drywall sealed to top plate at all unconditioned attic/wall interface using caulk, foam, drywall adhesive (but not other construction adhesive), or equivalent material. Either apply sealant directly between dry wall and top plate or to the seam between the two from the attic above.

5.2.4 Rough opening around windows \& exterior doors sealed with caulk or foam

HVAC System Quality Installation Contractor Checklist

1. Whole-Building Mechanical Ventilation Design

1.1 Ventilation system installed that has been designed to meet ASHRAE 62.2-2010 requirements including, but not limited to, requirements in Items 1.2-1.5. 


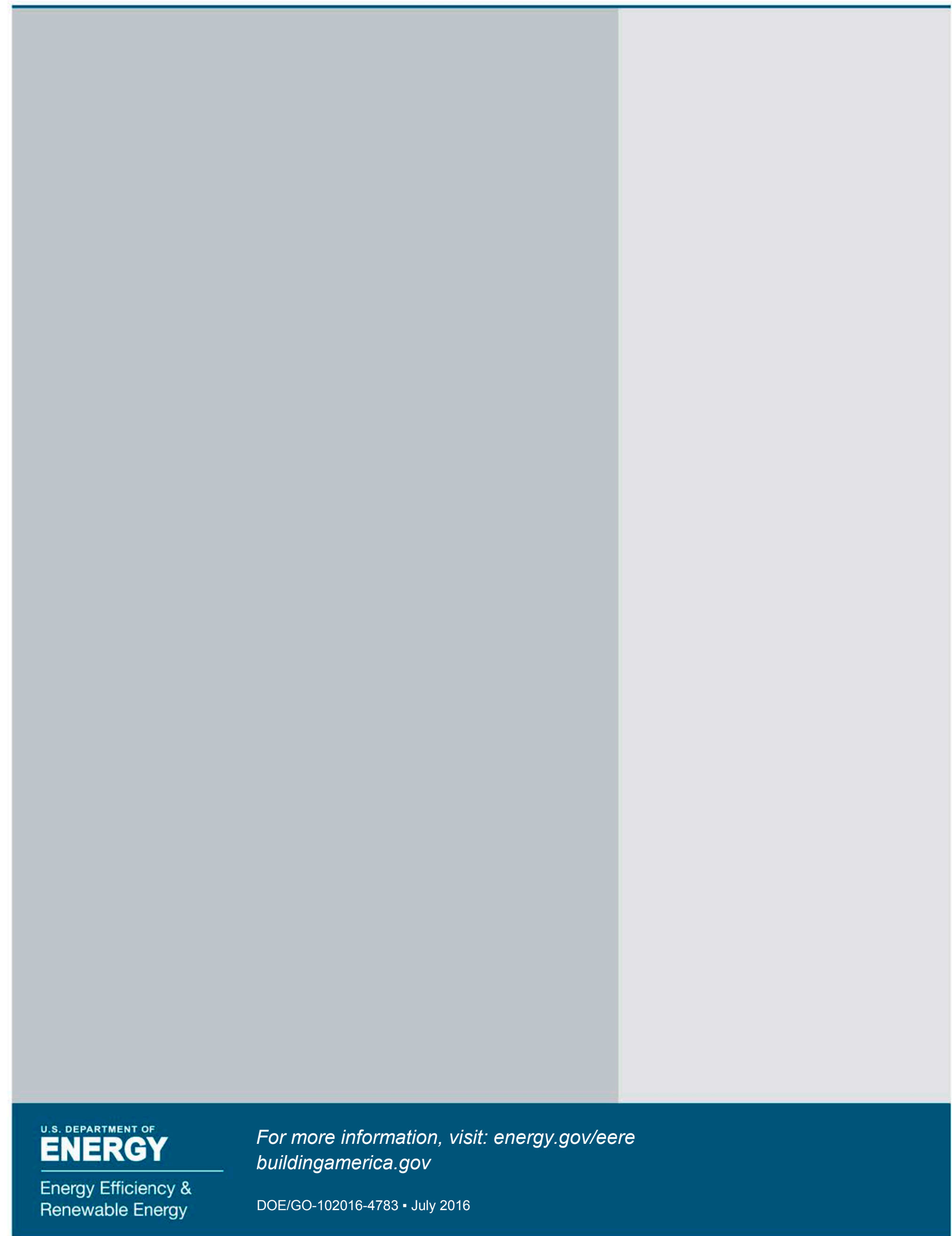

